\title{
OPTIMASI DESAIN STENT PLA MENGGUNAKAN METODE RESPONSE SURFACE (RSM) UNTUK MEMPEROLAH FLEKSIBILITAS TERBAIK
}

\author{
Sukiman $B^{1 *}$ dan Alva Edy Tontowi ${ }^{1}$ \\ ${ }^{1}$ Departemen Teknik Mesin dan Industri \\ Fakultas Teknik Universitas Gadjah Mada \\ Submisi:09-05-2018; Revisi: 24-08-2018; Diterima: 26-08-2018
}

\begin{abstract}
The stent installation is one of cardiovascular disease treatments which is selected the most to handle patients with blood vessel disease. As the demand for stents increases, more researches are aimed at developing them. This study aims to obtain the optimal link design to produce the best flexibility to the change of stent angle with minimum stress so as not to injure blood vessel plaque. In this study, the stents are polymer stent with different types of links made with PLA materials with strut mirror $(S><)$ design. The study was conducted on two stent configurations, namely crimped and expanded to determine the ability of angular change and maximum stress experienced by both when bending moment applied. The bending moment test was done through simulation based on finite element method in software Abaqus 6.14. The simulation results were then used as a model-making reference to determine the desired optimization design using the help of Minitab 18 software based on the response surface method. The results of this study indicate that the best optimal flexibility on crimped stent L1 to L5, which is the highest flexibility with von mises stress in the safety limit can be obtained based on a combination of link design parameters in the form of bending moment of $0.0074 \mathrm{~N}$.mm with a thickness of $100 \mu \mathrm{m} \mathrm{L3}$, and 0,0087 N.mm with a thickness of $106 \mu \mathrm{m}$ L5. While at the expanded stent L1 to L5, the optimal link design parameter value for obtaining the best flexibility with von mises stress within the safety limit is a bending moment of 0.0075 N.mm with a thickness of $63.78 \mu \mathrm{m} \mathrm{L3}$, and 0.0067 N.mm with a thickness of $70 \mu \mathrm{m} \mathrm{L5.}$
\end{abstract}

Keywords: Bending moment; Curvature index; Flexibility; Response surface methods; Stent L1 to L5 design; Stent with different types of links; Von mises.

\begin{abstract}
ABSTRAK
Proses pemasangan stent merupakan salah satu jenis penanganan penyakit kardiovaskuler yang paling banyak dipilih untuk menangani pasien penderita penyempitan pembuluh darah. Seiring dengan meningkatnya permintaan stent, semakin banyak pula penelitian untuk mengembangkannya. Penelitian ini bertujuan untuk mendapatkan desain link yang optimal untuk menghasilkan fleksibilitas terbaik terhadap perubahan sudut stent dengan tegangan minimum supaya tidak melukai plak pembuluh darah. Pada penelitian ini, stent yang diteliti adalah stent polimer yang jenisnya berbedabeda link menggunakan material PLA dengan desain strut mirror $(\mathrm{S}><)$. Penelitian dilakukan pada dua konfigurasi stent, yaitu pada crimped dan expanded untuk mengetahui kemampuan perubahan sudut dan tegangan maksimum yang dialami oleh keduanya setelah diberikan bending moment. Pengujian bending moment dilakukan melalui simulasi berdasarkan metode elemen hingga pada software Abaqus
\end{abstract}

*Corresponding author: sukimanb21@gmail.com

Copyright (C) 2018 THE AUTHOR(S).This article is distributed under a Creative Commons Attribution-Share Alike 4.0 International license. 
6.14. Hasil simulasi kemudian dijadikan acuan pembuatan model guna menentukan desain optimasi yang diinginkan menggunakan bantuan software Minitab 18 berdasarkan metode response surface. Hasil penelitian ini menunjukkan fleksibilitas optimal terbaik pada crimped stent L1 sampai dengan L5, yaitu fleksibilitas tertinggi dengan tegangan von mises dalam batas aman dapat diperoleh berdasarkan kombinasi parameter desain link berupa bending momen sebesar 0,0074 N.mm dengan ketebalan $100 \mu \mathrm{m}$ L3, dan 0,0087 N.mm dengan ketebalan $106 \mu \mathrm{m}$ L5. Sementara pada expanded stent L1 sampai dengan L5, nilai parameter desain link yang optimal untuk mendapatkan fleksibilitas terbaik dengan tegangan von mises dalam batas aman adalah bending moment sebesar 0,0075 N.mm dengan ketebalan 63,78 $\mu \mathrm{m}$ L3, dan 0,0067 N.mm dengan ketebalan $70 \mu \mathrm{m}$ L5.

Kata Kunci: Bending moment; Curvature index; Desain stent L1 sampai dengan L5; Fleksibilitas; Metode response surface; Stent berbeda-beda link; Von mises.

\section{PENGANTAR}

Menurut Kementerian Kesehatan Republik Indonesia tahun 2013, setiap tahunnya terdapat lebih dari 36 juta orang yang meninggal karena penyakit tidak menular. Berdasarkan diagnosis dokter, prevalensi penyakit jantung koroner di Indonesia tahun 2013 sebesar 0,5\% atau diperkirakan sekitar 883.447 orang, sedangkan berdasarkan diagnosis dokter/gejala sebesar $1,5 \%$ atau diperkirakan sekitar 2.650 .340 orang. (Kementerian Kesehatan RI, 2013). Untuk menangani penyumbatan yang terjadi, terdapat 3 (tiga) jenis penanganan yang dapat dilakukan. Jenis-jenis penanganan tersebut antara lain tindakan angioplasty, yaitu dengan memperlebar pembuluh darah menggunakan kateter balon dan operasi bypass, yaitu dengan membentuk pembuluh darah baru sebagai pengganti pembuluh arteri jantung menggunakan pembuluh arteri bagian tubuh lain, dan pemasangan stent untuk menyangga pembuluh darah supaya tidak kembali terjadi penyempitan. Menurut Erbel $d k k$ (1998) bahwa stent juga dianggap lebih efektif untuk mencegah restenosis dibanding angioplasty biasa yang menggunakan kateter balon saja. Pada tahun 2012, kebutuhan drug eluting stent (DES) dan bare metal stent (BMS) di tiga rumah sakit besar, yaitu RS Harapan Kita, RS Sardjito, dan RS Soetomo, secara keseluruhan mencapai angka 4.000 buah (Tontowi dkk, 2013). Akan tetapi, kebutuhan tersebut masih dipenuhi oleh stent impor karena belum adanya perusahaan lokal di Indonesia yang memproduksi stent. Dalam memproduksi stent, tentunya terdapat banyak aspek yang harus diperhatikan supaya pembuatan stent dapat memenuhi kriteria, terutama dari sudut pandang dokter selaku tenaga kesehatan. Ketika dimasukkan ke dalam pembuluh darah, stent memiliki konfigurasi crimped atau belum dikembangkan. Setelah sampai pada titik yang dituju, crimped stent kemudian dikembangkan dengan besaran tekanan tertentu hingga mencapai diameter ekspansi yang diperlukan supaya dapat menyangga plak pada dinding pembuluh darah. Menurut Beule (2008), ease of delivery tersebut ditunjukkan oleh fleksibilitas dari suatu stent, yaitu kemampuan stent dalam mengakomodasi lengkungan dan sudut dari pembuluh darah. Selain itu, fleksibilitas yang baik juga diperlukan guna mengurangi tegangan yang terjadi antara expanded stent dengan jaringan di sekitarnya. Sedangkan, expanded stent dapat menyesuaikan bentuknya terhadap lengkungan pembuluh darah sekaligus meminimalkan timbulnya luka pada dinding pembuluh. Menurut Li $d k k$ (2009) bahwa metode numerik dilakukan melalui simulasi yang dilakukan dengan bantuan komputer. Metode ini memiliki keunggulan dalam fleksibilitas dan biaya dibanding dengan percobaan-percobaan yang dilakukan di rumah sakit dan laboratorium. Selain itu, menurut $\mathrm{Wu}$ $d k k$ (2007) bahwa struktur stent yang sangat kecil serta biaya fabrikasi prototype-nya yang tinggi menyebabkan metode ini banyak digunakan dalam penelitian-penelitian terkait. Penelitian mengenai fleksibilitas berdasarkan metode numerik, khususnya metode elemen hingga atau biasa disebut Finite Element Method (FEM), salah satunya dilakukan oleh Petrini $d k k$ (2004). Penelitian serupa dilakukan oleh Wu dkk (2007) yang melakukan pengujian fleksibilitas pada unit stent dan whole stent berbahan baku stainless steel 316L pada konfigurasi expanded. 
Penelitian selanjutnya terkait fleksibilitas pada stent dilakukan oleh Pant $d k k$ (2012). Penelitian selanjutnya dilakukan oleh Bobel $d k k$ (2015) yang melakukan pengujian fleksibilitas dengan mekanis pada stent polimer yang komersial dan stent komersial yang digunakan tipe Multilink, Absorb dan Zig-Zag yang berbahan baku polyL-latide-acid (PLLA) pada konfigurasi crimped dan expanded. pada penelitian ini dilakukan optimasi desain stent yang bertujuan untuk mengetahui nilai optimal sebagai acuan perbandingan produksi stent. Nilai fungsi tujuan yang akan dilihat adalah fleksibilitas yang ditunjukkan oleh curvature index, serta tegangan maksimum yang dialami pada stent sebagai akibat dari pemberian bending moment yang ditunjukkan oleh nilai Von Mises. Hasil yang diharapkan adalah desain stent pada suatu ketebalan dengan besaran momen tertentu yang dapat menghasilkan fleksibilitas tertinggi dengan tegangan maksimum dalam batas aman. Skenario desain disusun berdasarkan metode response surface (RSM). Penentuan parameter ketebalan mengacu pada stent komersial dan desain link komersial yang ada di pasaran, yaitu PRO-Kinetic Energy stent yang diproduksi oleh Biotronik yang memiliki ketebalan strut $60 \mu \mathrm{m}$. Pada penelitian ini, bending moment akan diberikan pada polymer stent (PS) dengan material Polylactic Acid (PLA) dengan profil desain strut berlawanan arah (mirror) pada desain link yang berbedabeda. Optimasi akan dilakukan pada dua konfigurasi stent, yaitu pada konfigurasi crimped dan expanded dengan ketebalan 70, 85, dan $100 \mu \mathrm{m}$ menggunakan Response Surface Method (RSM).

Objek penelitian ini adalah polymer stent berbahan Polylactic Acid (PLA) dengan mekanisme ekspansi balloon-expandable. Stent yang diteliti adalah jenis stent close cell dengan strut berlawanan arah $(S><)$, yaitu strut yang letaknya berlawanan arah dengan longitudinal axis. stent yang diteliti adalah unit stent dengan konfigurasi crimped, yaitu stent yang belum diekspansikan dengan ukuran deliverable, dan konfigurasi expanded, yaitu stent ketika telah diekspansikan dan terpasang pada titik bagian pembuluh darah yang dikehendaki. Desain strut konfigurasi crimped memiliki ukuran diameter sebesar 1,2 $\mathrm{mm}$ pada jenis ketebalan (70, 85, dan $100 \mu \mathrm{m})$ serta Panjang sebesar 4,2 $\mathrm{mm}$ dan desain strut konfigurasi Expanded memiliki ukuran diameter sebesar 3,1 mm pada jenis ketebalan $(70,85$, dan $100 \mu \mathrm{m})$ serta Panjang sebesar 3,7 mm.

Alat yang akan digunakan yaitu, Autodesk Inventor Professional 2018, Abaqus 6.14, Minitab 18, Mesin uji Tarik HT-2402 merek Hung Ta dengan kapasitas 2000 kN. Berikut adalah desain uji tarik menggunakan standar ASTM D638 (Gambar 1) dan hasil uji tarik material properties dari bahan baku polymer stent yang diteliti Pada (Tabel 1):

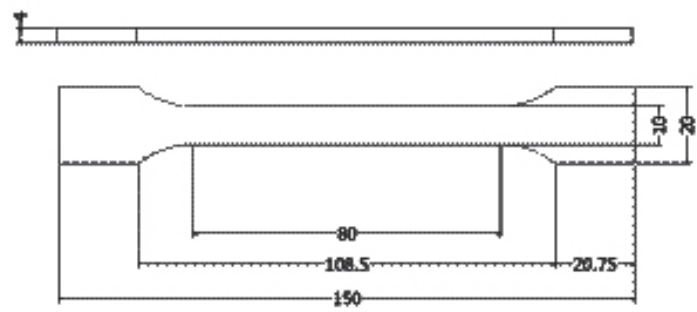

Gambar 1.

Desain Standar ASTM D638

Tabel 1.

Material Properties Polylactic Acid (PLA)

\begin{tabular}{cc}
\hline Mechanical Properties & Nilai \\
Yield Stress (oy), MPa & 38,5 \\
Ultimate Tensile Strength, MPa & 40,64 \\
Modulus Young (E), GPa & 1586 \\
Poisson's Ratio (v) & 0,3 \\
Density $(\rho), \mathrm{g} / \mathrm{cm} 3$ & 1,25 \\
\hline
\end{tabular}

Ilustrasi dari tahapan penelitian yang dilakukan

1. Mendesain stent 2D dan 3D.

Perancangan stent dilakukan dengan menggunakan software Autodesk Inventor Professional 2018.

2. Simulasi desain stent dengan Abaqus 6.14. Dilakukan penginputan data berupa material properties dari Polylactic Acid (PLA) dengan jenis material berupa data elastis. Kemudian, langkah-langkah simulasi yang dipakai didefinisikan ke dalam Abaqus 6.14 
3. Analisis data hasil simulasi.

Pembebanan yang menghasilkan data berupa perubahan sudut dan tegangan Von Mises yang terjadi pada stent. Perubahan sudut yang diperoleh dalam satuan radian, sehingga harus dikonversikan dahulu ke dalam pengukuran fleksibilitas yaitu curvature index ( $\mathrm{rad} / \mathrm{mm}$ ).

4. Menentukan faktor dan level penelitian Dilakukan penentuan faktor dan level penelitian untuk merancang desain eksperimen.Penentuan level dari tiap faktor dilakukan berdasarkan analisis data yang telah dilakukan pada poin sebelumnya.

Tabel 2.

Kode level dan nilai asli parameter desain

\begin{tabular}{|c|c|c|c|c|}
\hline \multirow{2}{*}{ Faktor } & \multirow{2}{*}{ Level } & \multicolumn{2}{|c|}{ Actual Variabel } & \multirow{2}{*}{ Satuan } \\
\hline & & Crimped & Expanded & \\
\hline \multirow{2}{*}{ Momen } & - & 0,001 & 0,001 & \multirow{2}{*}{ N.mm } \\
\hline & + & 0,011 & 0,011 & \\
\hline \multirow{2}{*}{ Tebal } & - & 70 & 70 & \multirow{2}{*}{$\mu \mathrm{m}$} \\
\hline & + & 100 & 100 & \\
\hline
\end{tabular}

5. Merancang eksperimen orde pertama.

Dibuat perancangan eksperimen untuk orde pertama, baik untuk stent pada konfigurasi crimped maupun expanded.

6. Mendesain stent sesuai rancangan eksperimen orde pertama.

Dilakukan pembuatan desain stent dengan ketebalan 70, 85 dan $100 \mu \mathrm{m}$.

7. Melakukan simulasi orde pertama.

Rancangan orde pertama kemudian disimulasikan untuk mendapatkan nilai Curvature Index dan Von Mises.

8. Analisis data dan hasil simulasi. Menghasilkan data berupa perubahan sudut dan tegangan Von Mises dari hasil simulasi Abaqus 6.14.

9. Menentukan pengelolahan data dari orde pertama.

Model orde pertama disusun berdasarkan analisis regresi menggunakan software Minitab 18 yang akan menghasilkan model dengan persamaan.

$$
\hat{y}=\beta_{0}+\beta_{1} x_{1}+\beta_{2} x_{2}
$$

10.Uji kecukupan model orde pertama.

Uji kecukupan data pada orde pertama dilakukan dengan melihat hasil ANOVA pada Minitab 18. Model dikatakan mencukupi jika nilai P-value-nya $>\mathrm{a}$, sehingga akan gagal menolak $H_{0}$. Nilai a yang digunakan adalah 0,05.

11. Merancangan orde kedua.

Rancangan orde kedua adalah central compisiteb design (CCD) yang terdiri dari rancangan $2^{2}$ faktorial di tambahkan dengan 5 centar point, dan 4 axial point, sehingga jumlah pengamatan orde kedua adalah 13.

12.Mendesain Stent Sesuai Rancangan Eksperimen orde kedua.

Dilakukan pembuatan desain stent dengan ketebalan 63,79 dan 106,21 $\mu \mathrm{m}$. Dimensi desain 2D dan tampak desain 3D Crimped stent dan expanded stent ditunjukkan pada Gambar 2.
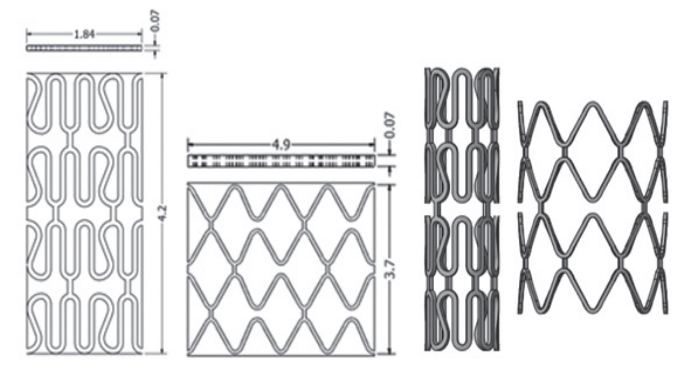

Gambar 2.

Crimped stent dan expanded stent dengan ketebalan 63,79 dan

106,21 m: (a) Sektsa dasar.; (b) Bentuk 3D

13. Melakukan Simulasi Sesuai orde kedua.

Dilakukan simulasi pembebanan dengan memberikan bending moment sesuai dengan skenario orde kedua yang telah dibuat. Berikut adalah persamaan curvature index (CI):

$\mathrm{X}=\frac{\Delta \phi}{\mathrm{L}}$ 


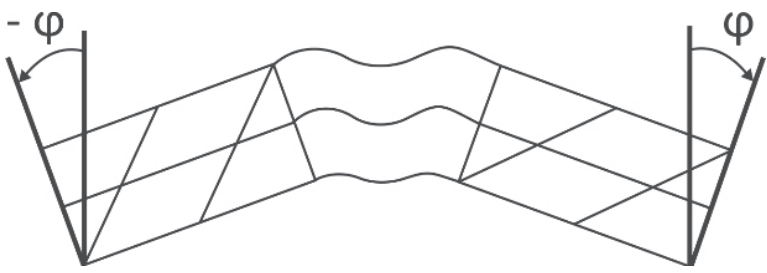

Gambar 3.

Perubahan Sudut pada Stent Akibat Bending Moment

14. Melakukan Pengolahan Data orde kedua dan model orde kedua.

Model orde kedua analisis yang dilakukan akan menghasilkan model orde kedua yang memiliki bentuk persamaan umum sebagai berikut.

$$
\begin{aligned}
\hat{y}= & \beta_{0}+\beta_{1} x_{1}+\beta_{2} x_{2}+ \\
& \beta_{3} x_{1}^{2}+\beta_{4} x_{2}^{2}+\beta_{1} x_{1} x_{2}
\end{aligned}
$$

15.Uji kecukupan model orde kedua.

Uji kecukupan data pada model orde kedua dilakukan dengan melihat hasil analysis of variance pada Minitab 18.

16. Melakukan Validasi Model.

Validasi dilakukan melalui pengujian statistik terhadap data eksperimen dengan data hasil perhitungan model matematis yang dihasilkan.

17. Menentukan Parameter Desain untuk Respon Optimal.

Optimasi dilakukan menggunakan bantuan response optimizer pada software Minitab 18.

18. Menganalisis hasil.

Dilakukan analisis hasil untuk membandingkan hasil respon dari perhitungan menggunakan model yang telah dibangun dengan respon aktual dari eksperimen yang dilakukan.

Tabel 3.

\begin{tabular}{|c|c|c|c|c|c|c|c|}
\hline \multicolumn{8}{|c|}{ L1 } \\
\hline \multirow{2}{*}{$\begin{array}{l}\text { Run } \\
\text { Test }\end{array}$} & \multicolumn{2}{|c|}{ Coded Variables } & \multicolumn{2}{|c|}{$\begin{array}{l}\text { Uncoded } \\
\text { Variables }\end{array}$} & \multicolumn{2}{|c|}{ Response } & \multirow[b]{2}{*}{ Kode Parameter } \\
\hline & Momen & Tebal & $\begin{array}{l}\text { Momen } \\
\text { (N.mm) }\end{array}$ & $\begin{array}{l}\text { Tebal } \\
\text { (mm) }\end{array}$ & $\begin{array}{c}\mathrm{CI} \\
(\mathrm{rad} / \mathrm{mm})\end{array}$ & $\begin{array}{c}\mathrm{VM} \\
(\mathrm{MPa})\end{array}$ & \\
\hline 1 & -1 & -1 & 0,001 & 70 & $3,21 \mathrm{E}-03$ & 4,5 & L.1M0001TB70 \\
\hline 2 & 1 & -1 & 0,011 & 70 & $3,97 \mathrm{E}-02$ & 18,35 & L.M0011TB70 \\
\hline 3 & -1 & 1 & 0,001 & 100 & $2,35 \mathrm{E}-03$ & 3,34 & L.M0001TB100 \\
\hline 4 & 1 & 1 & 0,011 & 100 & $2,76 \mathrm{E}-02$ & 16,8 & L.M0011TB100 \\
\hline 5 & $\mathbf{0}$ & $\mathbf{0}$ & 0,006 & 85 & $1,63 \mathrm{E}-02$ & 12,76 & L.1M0006TB85 \\
\hline 6 & $\mathbf{0}$ & $\mathbf{0}$ & 0,006 & 85 & $1,63 \mathrm{E}-02$ & 12,76 & L.1M0006TB85 \\
\hline 7 & $\mathbf{0}$ & $\mathbf{0}$ & 0,006 & 85 & $1,63 \mathrm{E}-02$ & 12,76 & L.M0006TB85 \\
\hline 8 & $\mathbf{0}$ & $\mathbf{0}$ & 0,006 & 85 & $1,63 \mathrm{E}-02$ & 12,76 & L.1M0006TB85 \\
\hline 9 & $\mathbf{0}$ & $\mathbf{0}$ & 0,006 & 85 & $1,63 \mathrm{E}-02$ & 12,76 & L.M0006TB85 \\
\hline \multicolumn{8}{|c|}{ L2. } \\
\hline 1 & -1 & -1 & 0,001 & 70 & $5,60 \mathrm{E}-03$ & 4,63 & L.2M0001TB70 \\
\hline 2 & 1 & -1 & 0,011 & 70 & $9,91 \mathrm{E}-02$ & 48,35 & L.2M0011TB70 \\
\hline 3 & -1 & 1 & 0,001 & 100 & $2,92 \mathrm{E}-03$ & 3,48 & L.2M0001TB100 \\
\hline 4 & 1 & 1 & 0,011 & 100 & $4,16 \mathrm{E}-02$ & 23,36 & L.2M0011TB100 \\
\hline 5 & $\mathbf{0}$ & $\mathbf{0}$ & 0,006 & 85 & $2,33 \mathrm{E}-02$ & 14,14 & L.2M0006TB85 \\
\hline 6 & $\mathbf{0}$ & $\mathbf{0}$ & 0,006 & 85 & $2,33 \mathrm{E}-02$ & 14,14 & L.2M0006TB85 \\
\hline 7 & $\mathbf{0}$ & $\mathbf{0}$ & 0,006 & 85 & $2,33 \mathrm{E}-02$ & 14,14 & L.2M0006TB85 \\
\hline 8 & $\mathbf{0}$ & $\mathbf{0}$ & 0,006 & 85 & $2,33 \mathrm{E}-02$ & 14,14 & L.2M0006TB85 \\
\hline 9 & $\mathbf{0}$ & $\mathbf{0}$ & 0,006 & 85 & $2,33 \mathrm{E}-02$ & 14,14 & L.2M0006TB85 \\
\hline
\end{tabular}

Hasil eksperimen crimped stent orde pertama 
SUKIMAN B DAN ALVA EDY TONTOWI OPTIMASI DESAIN STENT PLA MENGGUNAKAN METODE RESPONSE SURFACE (RSM) UNTUK MEMPEROLAH FLEKSIBILITAS TERBAIK

\begin{tabular}{|c|c|c|c|c|c|c|c|}
\hline \multirow{2}{*}{$\begin{array}{l}\text { Run } \\
\text { Test }\end{array}$} & \multicolumn{2}{|c|}{ Coded Variables } & \multicolumn{2}{|c|}{$\begin{array}{l}\text { Uncoded } \\
\text { Variables }\end{array}$} & \multicolumn{2}{|c|}{ Response } & \multirow[b]{2}{*}{ Kode Parameter } \\
\hline & Momen & Tebal & $\begin{array}{l}\text { Momen } \\
\text { (N.mm) }\end{array}$ & $\begin{array}{l}\text { Tebal } \\
(\mathrm{mm})\end{array}$ & $\underset{(\mathrm{rad} / \mathrm{mm})}{\mathrm{Cl}}$ & $\begin{array}{c}\mathrm{VM} \\
(\mathrm{MPa})\end{array}$ & \\
\hline \multicolumn{8}{|c|}{ L.3 } \\
\hline 1 & -1 & -1 & 0,001 & 70 & $1,02 \mathrm{E}-02$ & 7,93 & L.3M0001TB70 \\
\hline 2 & 1 & -1 & 0,011 & 70 & $1,42 \mathrm{E}-01$ & 60,69 & L.3M0011TB70 \\
\hline 3 & -1 & 1 & 0,001 & 100 & $7,52 \mathrm{E}-03$ & 5,2 & L.3M0001TB100 \\
\hline 4 & 1 & 1 & 0,011 & 100 & $1,15 \mathrm{E}-01$ & 47,7 & L.3M0011TB100 \\
\hline 5 & $\mathbf{0}$ & $\mathbf{0}$ & 0,006 & 85 & $6,60 \mathrm{E}-02$ & 30,82 & L.3M0006TB85 \\
\hline 6 & $\mathbf{0}$ & $\mathbf{0}$ & 0,006 & 85 & $6,60 \mathrm{E}-02$ & 30,82 & L.3M0006TB85 \\
\hline 7 & $\mathbf{0}$ & $\mathbf{0}$ & 0,006 & 85 & $6,60 \mathrm{E}-02$ & 30,82 & L.3M0006TB85 \\
\hline 8 & $\mathbf{0}$ & $\mathbf{0}$ & 0,006 & 85 & $6,60 \mathrm{E}-02$ & 30,82 & L.3M0006TB85 \\
\hline 9 & $\mathbf{0}$ & 0 & 0,006 & 85 & $6,60 \mathrm{E}-02$ & 30,82 & L.3M0006TB85 \\
\hline \multicolumn{8}{|c|}{ L4 } \\
\hline 1 & -1 & -1 & 0,001 & 70 & $5,68 \mathrm{E}-03$ & 7,18 & L4M0001TB70 \\
\hline 2 & 1 & -1 & 0,011 & 70 & 9,35E-02 & 60,29 & L4M0011TB70 \\
\hline 3 & -1 & 1 & 0,001 & 100 & $4,13 \mathrm{E}-03$ & 5,12 & L4M0001TB100 \\
\hline 4 & 1 & 1 & 0,011 & 100 & $5,70 \mathrm{E}-02$ & 56,17 & L4M0011TB100 \\
\hline 5 & $\mathbf{0}$ & $\mathbf{0}$ & 0,006 & 85 & $3,04 \mathrm{E}-02$ & 26,56 & L4M0006TB85 \\
\hline 6 & $\mathbf{0}$ & $\mathbf{0}$ & 0,006 & 85 & $3,04 \mathrm{E}-02$ & 26,56 & L4M0006TB85 \\
\hline 7 & $\mathbf{0}$ & $\mathbf{0}$ & 0,006 & 85 & $3,04 \mathrm{E}-02$ & 26,56 & L4M0006TB85 \\
\hline 8 & $\mathbf{0}$ & $\mathbf{0}$ & 0,006 & 85 & $3,04 \mathrm{E}-02$ & 26,56 & L4M0006TB85 \\
\hline 9 & $\mathbf{0}$ & $\mathbf{0}$ & 0,006 & 85 & $3,04 \mathrm{E}-02$ & 26,56 & L4M0006TB85 \\
\hline \multicolumn{8}{|c|}{ L.S } \\
\hline 1 & -1 & -1 & 0,001 & 70 & $1,47 \mathrm{E}-02$ & 7,78 & L.5M0001TB70 \\
\hline 2 & 1 & -1 & 0,011 & 70 & $1,25 \mathrm{E}-01$ & 42,43 & L.SM0011TB70 \\
\hline 3 & -1 & 1 & 0,001 & 100 & $1,02 \mathrm{E}-02$ & 4,86 & L.5M0001TB100 \\
\hline 4 & 1 & 1 & 0,011 & 100 & $1,02 \mathrm{E}-01$ & 32,74 & L.5M0011TB100 \\
\hline 5 & $\mathbf{0}$ & $\mathbf{0}$ & 0,006 & 85 & $7,26 \mathrm{E}-02$ & 24,31 & L.5M0006TB85 \\
\hline 6 & $\mathbf{0}$ & $\mathbf{0}$ & 0,006 & 85 & $7,26 \mathrm{E}-02$ & 24,31 & L.5M0006TB85 \\
\hline 7 & $\mathbf{0}$ & $\mathbf{0}$ & 0,006 & 85 & $7,26 \mathrm{E}-02$ & 24,31 & L.5M0006TB85 \\
\hline 8 & $\mathbf{0}$ & $\mathbf{0}$ & 0,006 & 85 & $7,26 \mathrm{E}-02$ & 24,31 & L.5M0006TB85 \\
\hline 9 & $\mathbf{0}$ & $\mathbf{0}$ & 0,006 & 85 & $7,26 \mathrm{E}-02$ & 24,31 & LSM0006TB85 \\
\hline
\end{tabular}

\section{HASIL DAN PEMBAHASAN}

Analisis Data untuk Optimasi pada Crimped Stent. Rancangan eksperimen terdiri atas 2 (dua) faktor yang ditambah dengan 5 (lima) titik pusat (center point), sehingga jumlah totalnya adalah 9 (sembilan) eksperimen. Faktor-faktor yang digunakan adalah ketebalan stent dan momen tekuk (bending moment) yang diberikan pada stent. Sedangkan respon yang akan dianalisis adalah curvature index (CI) dan tegangan Von Mises (VM).

Data hasil eksperimen orde pertama kemudian dianalisis dengan bantuan software
Minitab 18 untuk mendapatkan model orde pertama yang menggambarkan hubungan antara variabel eksplanatori (faktor) terhadap variabel respon. model dasar orde pertama yang diperoleh untuk tiap respon.

1. Model Respon Curvature Index dan Model Respon Von Mises Terhadap L1

a. Model Respon Curvature Index $\hat{y}_{\mathrm{CI}}=0,017135+0,01545 x_{1}-0,00324 x_{2}$

b. Model Respon Von Mises

$$
\hat{\mathrm{y}}_{\mathrm{VM}}=11,869+6,827 x_{1}-0,68 x_{2}
$$


2. Model Respon Curvature Index dan Model Respon Von Mises Terhadap L2

a. Model Respon Curvature Index $\hat{\mathrm{y}}_{\mathrm{CI}}=0,02951+0,03304 x_{1}-0,01504 x_{2}$

b. Model Respon Von Mises

$$
\hat{\mathrm{y}}_{\mathrm{VM}}=16,73+15,9 x_{1}-6,53 x_{2}
$$

3. Model Respon Curvature Index dan Model Respon Von Mises Terhadap L3

a. Model Respon Curvature Index $\hat{\mathrm{y}}_{\mathrm{CI}}=0,06719+0,05982 x_{1}-0,00733 x_{2}$

b. Model Respon Von Mises

$$
\hat{y}_{\mathrm{VM}}=30,625+23,82 x_{1}-3,93 x_{2}
$$

4. Model Respon Curvature Index dan Model Respon Von Mises Terhadap L4

a. Model Respon Curvature Index

$$
\hat{y}_{\mathrm{CI}}=0,03469+0,03518 x_{1}-0,00952 x_{2}
$$

b. Model Respon Von Mises

$$
\hat{y}_{\mathrm{VM}}=29,06+26,04 x_{1}-1,55 x_{2}
$$

5. Model Respon Curvature Index dan Model Respon Von Mises Terhadap L5

a. Model Respon Curvature Index $\hat{y}_{\mathrm{CI}}=0,0683+0,05051-0,00707 x_{2}$

b. Model Respon Von Mises $\hat{y}_{\mathrm{VM}}=23,265+15,633 x_{1}-3,152 x_{2}$

\section{Analysis of Variance (ANOVA)}

Dilakukan pengujian statistik menggunakan Analysis of Variance (ANOVA) untuk mengetahui faktor-faktor yang signifikan pada tiap model respon.

Tabel 4.

Hasil ANOVA orde pertama pada respon Curvature Index (crimped stent)

\begin{tabular}{lcccccc}
\hline \multirow{2}{*}{ Source } & DF & $\begin{array}{c}\text { P-Value } \\
\text { L1 }\end{array}$ & $\begin{array}{c}\text { P-Value } \\
\text { L2 }\end{array}$ & $\begin{array}{c}\text { P-Value } \\
\text { L3 }\end{array}$ & $\begin{array}{c}\text { P-Value } \\
\text { L4 }\end{array}$ & $\begin{array}{c}\text { P-Value } \\
\text { L5 }\end{array}$ \\
\hline Linear & 2 & 0 & 0,006 & 0 & 0,001 & 0 \\
Momen & 1 & 0 & 0,003 & 0 & 0 & 0 \\
Tebal & 1 & 0,047 & 0,076 & 0,03 & 0,086 & 0,091 \\
Curvature & 1 & 0,294 & 0,149 & 0,497 & 0,124 & 0,021 \\
\hline
\end{tabular}

Tabel 5.

Hasil ANOVA orde pertama pada respon von mises (crimped stent)

\begin{tabular}{lcccccc}
\hline Source & DF & $\begin{array}{c}\text { P-Value } \\
\text { L1 }\end{array}$ & $\begin{array}{c}\text { P-Value } \\
\text { L2 }\end{array}$ & $\begin{array}{c}\text { P-Value } \\
\text { L3 }\end{array}$ & $\begin{array}{c}\text { P-Value } \\
\text { L4 }\end{array}$ & $\begin{array}{c}\text { P-Value } \\
\text { L5 }\end{array}$ \\
\hline Linear & 2 & 0 & 0,004 & 0 & 0 & 0 \\
Momen & 1 & 0 & 0,002 & 0 & 0 & 0 \\
Tebal & 1 & 0,311 & 0,073 & 0,01 & 0,405 & 0,02 \\
Curvature & 1 & 0 & 0,165 & 0,785 & 0 & 0,067 \\
\hline
\end{tabular}

Tabel 6.

Uji kecukupan model order pertama

\begin{tabular}{ccccc}
\hline \multirow{2}{*}{ Respon } & \multicolumn{2}{c}{ P-value curvature } & & Status \\
\cline { 2 - 3 } & $\begin{array}{c}\text { Curvature } \\
\text { index }\end{array}$ & Von mises & $\alpha$ & \\
\hline L1 & 0,294 & 0 & 0,05 & Reject $\mathrm{H}_{0}$ \\
L2 & 0,149 & 0,165 & 0,05 & Fail to Reject $\mathrm{H}_{0}$ \\
L3 & 0,497 & 0,785 & 0,05 & Fail to Reject $\mathrm{H}_{0}$ \\
L4 & 0,124 & 0 & 0,05 & Reject $\mathrm{H}_{0}$ \\
L5 & 0,021 & 0,067 & 0,05 & Reject $\mathrm{H}_{0}$ \\
\hline
\end{tabular}

Rancangan orde dua menggunakan central compisiteb design (CCD), yang disusun menggunakan rancangan orde pertama ditambah empat axial point, sehingga jumlah test run yang harus dilakukan adalah 13 eksperimen. Dengan jumlah faktor $=2$, nilai a yang harusnya digunakan adalah $\sqrt{2}$ atau

\begin{tabular}{|c|c|c|c|c|c|c|c|}
\hline \multicolumn{8}{|c|}{ L1 } \\
\hline \multirow{2}{*}{$\begin{array}{l}\text { Rum } \\
\text { Test }\end{array}$} & \multicolumn{2}{|c|}{ Coded Variables } & \multicolumn{2}{|c|}{$\begin{array}{l}\text { Uncoded } \\
\text { Variables }\end{array}$} & \multicolumn{2}{|c|}{ Response } & \multirow[b]{2}{*}{ Kode Parameter } \\
\hline & Momen & Tebal & $\begin{array}{l}\text { Momen } \\
\text { (N.mm) }\end{array}$ & $\begin{array}{l}\text { Tebal } \\
(\mathrm{mm})\end{array}$ & $\begin{array}{c}\mathrm{Cl} \\
(\mathrm{rad} / \mathrm{mm})\end{array}$ & $\begin{array}{c}\mathrm{VM} \\
\text { (MPa) }\end{array}$ & \\
\hline 1 & -1 & -1 & 0,001 & 70 & $3,21 \mathrm{E}-03$ & 4,5 & L1M0001TB70 \\
\hline 2 & 1 & -1 & 0,011 & 70 & $3,97 \mathrm{E}-02$ & 18,35 & L1M0011TB70 \\
\hline 3 & -1 & 1 & 0,001 & 100 & $2,35 \mathrm{E}-03$ & 3,34 & L1M0001TB100 \\
\hline 4 & 1 & 1 & 0,011 & 100 & $2,76 \mathrm{E}-02$ & 16,8 & L1M0011TB100 \\
\hline 5 & $-1,41$ & 0 & 0,0011 & 85 & $1,25 \mathrm{E}-02$ & 4,26 & L1M00011TB85 \\
\hline 6 & $-1,41$ & 0 & 0,013 & 85 & $3,92 \mathrm{E}-02$ & 21,73 & L1M0013TB85 \\
\hline 7 & $\mathbf{0}$ & -1.41 & 0.006 & 63.79 & $2.17 \mathrm{E}-02$ & 13.9 & L1M0006ТВ63 \\
\hline 8 & o & 1,41 & 0,006 & 106,21 & $1,32 \mathrm{E}-02$ & 13,73 & L1M0006TB 106 \\
\hline 9 & o & 1 & 0,006 & 85 & $1,63 \mathrm{E}-02$ & 12,76 & L1M0006TB85 \\
\hline 10 & o & 1 & 0,006 & 85 & $1,63 \mathrm{E}-02$ & 12,76 & L1M0006TB85 \\
\hline 11 & o & 1 & 0,006 & 85 & $1,63 \mathrm{E}-02$ & 12,76 & L1M0006тВ85 \\
\hline 12 & o & 1 & 0,006 & 85 & $1,63 \mathrm{E}-02$ & 12,76 & L1M0006TB85 \\
\hline \multirow[t]{2}{*}{13} & o & 1 & 0,006 & 85 & $1,63 \mathrm{E}-02$ & 12,76 & L1M0006TB85 \\
\hline & \multicolumn{6}{|c|}{ L4 } & \\
\hline 1 & -1 & -1 & 0,001 & 70 & $5,68 \mathrm{E}-03$ & 7,18 & L4M0001TB70 \\
\hline 2 & 1 & -1 & 0,011 & 70 & $9,35 \mathrm{E}-02$ & 60,29 & L4M0011TB70 \\
\hline 3 & -1 & 1 & 0,001 & 100 & $4,13 \mathrm{E}-03$ & 5,12 & L4M0001TB 100 \\
\hline 4 & 1 & 1 & 0,011 & 100 & $5,70 \mathrm{E}-02$ & 56,17 & L4M0011TB100 \\
\hline 5 & $-1,41$ & 0 & 0,0011 & 85 & $5,27 \mathrm{E}-03$ & 6,11 & L4M00011TB85 \\
\hline 6 & $-1,41$ & 0 & 0,013 & 85 & $9,12 \mathrm{E}-02$ & 51,16 & L4M0013TB85 \\
\hline 7 & o & $-1,41$ & 0,006 & 63,79 & $4,37 \mathrm{E}-02$ & 52,49 & L4M0006TB63 \\
\hline 8 & o & 1,41 & 0,006 & 106,21 & $2,43 \mathrm{E}-02$ & 17,64 & L4M0006TB 106 \\
\hline 9 & o & 1 & 0,006 & 85 & $3,04 \mathrm{E}-02$ & 26,56 & L4M0006TB85 \\
\hline 10 & o & 1 & 0,006 & 85 & $3,04 \mathrm{E}-02$ & 26,56 & L4M0006TB85 \\
\hline 11 & 0 & 1 & 0,006 & 85 & $3,04 \mathrm{E}-02$ & 26,56 & L4M0006TB85 \\
\hline 12 & 0 & 1 & 0,006 & 85 & $3,04 \mathrm{E}-02$ & 26,56 & L4M0006TB85 \\
\hline \multirow[t]{2}{*}{13} & o & 1 & 0,006 & 85 & $3,04 \mathrm{E}-02$ & 26,56 & L4M0006TB85 \\
\hline & \multicolumn{6}{|c|}{ L5 } & \\
\hline 1 & -1 & -1 & 0,001 & 70 & $1,47 \mathrm{E}-02$ & 7,78 & L5M0001TB70 \\
\hline 2 & 1 & -1 & 0,011 & 70 & $1,25 \mathrm{E}-01$ & 42,43 & L5M0011TB70 \\
\hline 3 & -1 & 1 & 0,001 & 100 & $1,02 \mathrm{E}-02$ & 4,86 & L5M0001TB 100 \\
\hline 4 & 1 & 1 & 0,011 & 100 & $1,02 \mathrm{E}-01$ & 32,74 & L5M0011TB 100 \\
\hline 5 & $-1,41$ & 0 & 0,0011 & 85 & $1,33 \mathrm{E}-02$ & 6,79 & L5M00011TB85 \\
\hline 6 & $-1,41$ & 0 & 0,013 & 85 & $1,35 \mathrm{E}-01$ & 46,12 & L5M0013TB85 \\
\hline 7 & o & $-1,41$ & 0,006 & 63,79 & $9,70 \mathrm{E}-02$ & 34,51 & L5M0006TB63 \\
\hline 8 & o & 1,41 & 0,006 & 106,21 & $5,58 \mathrm{E}-02$ & 18,01 & L5M0006TB 106 \\
\hline 9 & o & 1 & 0,006 & 85 & $7,26 \mathrm{E}-02$ & 24,31 & L5M0006TB85 \\
\hline 10 & o & 1 & 0,006 & 85 & $7,26 \mathrm{E}-02$ & 24,31 & L5M0006TB85 \\
\hline 11 & $\mathbf{0}$ & 1 & 0,006 & 85 & $7,26 \mathrm{E}-02$ & 24,31 & L5M0006TB85 \\
\hline 12 & o & e & 0,006 & 85 & $7,26 \mathrm{E}-02$ & 24,31 & L5M0006TB85 \\
\hline 13 & o & 1 & 0,006 & 85 & $7,26 \mathrm{E}-02$ & 24,31 & L5M0006TB85 \\
\hline
\end{tabular}
1,4142 .

Tabel 7.

Hasil eksperimen crimped stent orde kedua 
1. Model Respon Curvature Index dan Model Respon Von Mises Terhadap L1

a. Model Respon Curvature Index

$\hat{\mathrm{y}}_{\mathrm{CI}}=0,01626+0,01245 x_{1}-0,00312 x_{2}+$ $0,00394 x_{1}^{2}-0,00025 x_{2}^{2}-0,00281 x_{1} x_{2}$

b. Model Respon Von Mises

$\hat{\mathrm{y}}_{\mathrm{vM}}=12,765+6,502 x_{1}-0,371 x_{2}-0,55$ $x_{1}^{2}-0,138 x_{2}^{2}-0,098 x_{1} x_{2}$

2. Model Respon Curvature Index dan Model Respon Von Mises Terhadap L4

a. Model Respon Curvature Index

$\hat{\mathrm{y}}_{\mathrm{CI}}=0,03038+0,03278 x_{1}-0,00819 x_{2}+$ $0,00866 x_{1}^{2}+0,00156 x_{2}^{2}-0,00875 x_{1} x_{2}$

b. Model Respon Von Mises

$\hat{\mathrm{y}}_{\mathrm{VM}}=26,56+20,98 x_{1}-6,93 x_{2}+1,12 x_{1}^{2}$ $+4,33 x_{2}^{2}-0,51 x_{1} x_{2}$

3. Model Respon Curvature Index dan Model Respon Von Mises Terhadap L5

a. Model Respon Curvature Index

$\hat{\mathrm{y}}_{\mathrm{CI}}=0,07257+0,04677 x_{1}-0,01083 x_{2}-$ $0,00231 x_{1}^{2}-0,00115 x_{2}^{2}-0,00479 x_{1} x_{2}$

b. Model Respon Von Mises

$\hat{\mathrm{y}}_{\mathrm{VM}}=24,31+14,77 x_{1}-4,49 x_{2}-0,03 x_{1}{ }_{1}$ $-0,13 x_{2}^{2}-1,69 x_{1} x_{2}$

Tabel 8. Hasil ANOVA orde kedua pada respon Curvature Index (crimped stent)

\begin{tabular}{lcccc}
\hline \multicolumn{1}{c}{ Source } & DF & $\begin{array}{c}\text { P-Value } \\
\text { L1 }\end{array}$ & $\begin{array}{c}\text { P-Value } \\
\text { L4 }\end{array}$ & $\begin{array}{c}\text { P-Value } \\
\text { L5 }\end{array}$ \\
\hline Linear & 2 & 0 & 0 & 0 \\
Momen & 1 & 0 & 0 & 0 \\
Tebal & 1 & 0,048 & 0 & 0,01 \\
Square & 2 & 0,066 & 0 & 0,764 \\
Momen*Momen & 1 & 0,026 & 0 & 0,506 \\
Tebal*Tebal & 1 & 0,864 & 0,211 & 0,737 \\
2-Way Interaction & 1 & 0,172 & 0,001 & 0,306 \\
\hline
\end{tabular}

Tabel 9. Hasil ANOVA orde kedua pada respon Von Mises (crimped stent)

\begin{tabular}{l|c|c|c|c}
\hline Source & DF & $\begin{array}{c}\text { P-Value } \\
\text { L1 }\end{array}$ & $\begin{array}{c}\text { P-Value } \\
\text { L4 }\end{array}$ & $\begin{array}{c}\text { P-Value } \\
\text { L5 }\end{array}$ \\
\hline Linear & 2 & 0 & 0 & 0 \\
\hline Momen & 1 & 0 & 0 & 0 \\
\hline Tebal & 1 & 0,506 & 0,042 & 0,003 \\
\hline Square & 2 & 0,64 & 0,395 & 0,993 \\
\hline Momen*Momen & 1 & 0,365 & 0,719 & 0,977 \\
\hline Tebal*Tebal & 1 & 0,814 & 0,191 & 0,911 \\
\hline 2-Way Interaction & 1 & 0,9 & 0,9 & 0,283 \\
\hline
\end{tabular}

Hasil pengujian menggunakan ANOVA juga menghasilkan nilai koefisien determinasi $\left(\mathrm{R}^{2}\right)$ yang menggambarkan besar pengaruh variabel-variabel bebas (faktor) yang digunakan terhadap variabel respon. Semakin besar nilai $\mathrm{R}^{2}$, maka semakin besar pengaruh variabel bebas tersebut terhadap variasi respon.

Tabel 10. Nilai $\mathrm{R}^{2}$ model dasar orde pertama (crimped stent)

\begin{tabular}{l|c|c|c}
\hline \multicolumn{4}{c}{$\mathrm{L} 2$} \\
\hline \multicolumn{1}{c|}{ Respon } & $\mathrm{R}^{2}$ & $\mathrm{R}^{2}$ (adj) & $\mathrm{R}^{2}-\mathrm{R}^{2}$ (adj) \\
\hline Curvature Index & $81,61 \%$ & $75,48 \%$ & $6,13 \%$ \\
\hline Von Mises & $84,48 \%$ & $79,30 \%$ & $5,18 \%$ \\
\hline \multicolumn{4}{|c}{$\mathrm{L} 3$} \\
\hline Curvature Index & $98,91 \%$ & $98,55 \%$ & $0,36 \%$ \\
\hline Von Mises & $98,87 \%$ & $98,49 \%$ & $0,38 \%$ \\
\hline
\end{tabular}

Tabel 11. Nilai $\mathrm{R}^{2}$ model dasar orde kedua (crimped stent)

\begin{tabular}{|c|c|c|c|}
\hline \multicolumn{4}{|c|}{ L1 } \\
\hline Respon & $\mathrm{R}^{2}$ & $\mathrm{R}^{2}(\operatorname{adj})$ & $R^{2}-R^{2}(\operatorname{adj})$ \\
\hline Curvature Index & $93,86 \%$ & $89,48 \%$ & $4,38 \%$ \\
\hline Von Mises & $95,61 \%$ & $92,47 \%$ & $3,14 \%$ \\
\hline \multicolumn{4}{|c|}{ L4 } \\
\hline Curvature Index & $99,38 \%$ & $98,93 \%$ & $0,45 \%$ \\
\hline Von Mises & $90,24 \%$ & $83,27 \%$ & $6,97 \%$ \\
\hline \multicolumn{4}{|c|}{ L5 } \\
\hline Curvature Index & $97,24 \%$ & $95,26 \%$ & $1,98 \%$ \\
\hline Von Mises & $97,01 \%$ & $94,87 \%$ & $2,14 \%$ \\
\hline
\end{tabular}

Validasi Model Regresi untuk Respon Curvature Index dan Von Mises. Kemudian, dilakukan pengujian hipotesis menggunakan F-test: Two Sample for Variances.

Tabel 12. F-test: Two Sample for Variances Curvature Index dan Von Mises (crimped Stent)

\begin{tabular}{ccccc}
\hline Respons & F & Fcritical & Status & Kode \\
\hline CI & 1,06948 & 2,68664 & Fail to Reject H0 & \multirow{2}{*}{ L1 } \\
VM & 1,04914 & 2,68664 & Fail to Reject H0 & \\
CI & 3,41739 & 3,4381 & Fail to Reject H0 & L2 \\
VM & 1,18425 & 3,4381 & Fail to Reject H0 & \\
CI & 1,01114 & 3,4381 & Fail to Reject H0 & L3 \\
VM & 1,01114 & 3,4381 & Fail to Reject H0 & \\
CI & 1,00937 & 2,68664 & Fail to Reject H0 & L4 \\
VM & 1,11211 & 2,68664 & Fail to Reject H0 & \\
CI & 1,03145 & 2,68664 & Fail to Reject H0 & L5 \\
VM & 1,0339 & 2,68664 & Fail to Reject H0 & \\
\hline
\end{tabular}


Selanjutnya, dilakukan t-test: Two-Sample Assuming Equal Variances.

Tabel 13. t-Test: Two-Sample Assuming Equal VariancesCurvature Index dan Von Mises (crimped Stent)

\begin{tabular}{ccccc}
\hline Respons & t-stst & tcritical & Status & Kode \\
\hline CI & 0,00075 & 2,0639 & Fail to Reject H0 & \multirow{2}{*}{ L1 } \\
VM & $-0,001$ & 2,0639 & Fail to Reject H0 & \\
CI & 1,324753 & 2,11991 & Fail to Reject H0 & L2 \\
VM & $-0,00078$ & 2,11991 & Fail to Reject H0 & \\
CI & 0,000181 & 2,11991 & Fail to Reject H0 & L3 \\
VM & $1,46 \mathrm{E}-05$ & 2,11991 & Fail to Reject H0 & \\
CI & 0,00183 & 2,0639 & Fail to Reject H0 & \multirow{2}{*}{ L4 } \\
VM & 0.00231 & 2,0639 & Fail to Reject H0 & \\
CI & $-0,0004$ & 2,0639 & Fail to Reject H0 & \multirow{2}{*}{ L5 } \\
VM & 0,00084 & 2,0639 & Fail to Reject H0 & \\
\hline
\end{tabular}

Analisis Data untuk Optimasi pada Expanded Stent. Rancangan eksperimen terdiri atas 2 (dua) faktor yang ditambah dengan 5 (lima) titik pusat (center point), sehingga jumlah totalnya adalah 9 eksperimen. Faktorfaktor yang digunakan adalah ketebalan stent dan momen tekuk (bending moment) yang diberikan pada stent. Sedangkan respon yang akan dianalisis adalah curvature index (CI) dan tegangan Von Mises (VM).

Tabel 14.

Hasil eksperimen expanded stent orde pertama

\begin{tabular}{|c|c|c|c|c|c|c|c|}
\hline \multicolumn{8}{|c|}{ L1 } \\
\hline \multirow{2}{*}{$\begin{array}{l}\text { Run } \\
\text { Test }\end{array}$} & \multicolumn{2}{|c|}{$\begin{array}{c}\text { Coded } \\
\text { Variables }\end{array}$} & \multicolumn{2}{|c|}{$\begin{array}{l}\text { Uncoded } \\
\text { Variables }\end{array}$} & \multicolumn{2}{|c|}{ Response } & \multirow{2}{*}{ Kode Parameter } \\
\hline & Momen & Tebal & $\begin{array}{l}\text { Momen } \\
(\text { N.mm) }\end{array}$ & $\begin{array}{l}\text { Tebal } \\
(\mathrm{mm})\end{array}$ & $\begin{array}{c}\mathrm{CI} \\
(\mathrm{rad} / \mathrm{mm})\end{array}$ & $\begin{array}{c}\mathrm{VM} \\
(\mathrm{MPa})\end{array}$ & \\
\hline 1 & -1 & -1 & 0,001 & 70 & $4,09 \mathrm{E}-03$ & 5,88 & L1M0001TB70 \\
\hline 2 & 1 & -1 & 0,011 & 70 & $6,75 \mathrm{E}-02$ & 24,02 & L1M0011TB70 \\
\hline 3 & -1 & 1 & 0,001 & 100 & $2,88 \mathrm{E}-03$ & 4,44 & L1M0001TB100 \\
\hline 4 & 1 & 1 & 0,011 & 100 & $3,66 \mathrm{E}-02$ & 22,11 & L1M0011TB100 \\
\hline 5 & 0 & 0 & 0,006 & 85 & $2,08 \mathrm{E}-02$ & 14,49 & L1M0006TB85 \\
\hline 6 & 0 & 0 & 0,006 & 85 & $2,08 \mathrm{E}-02$ & 14,49 & L1M0006TB85 \\
\hline 7 & 0 & 0 & 0,006 & 85 & $2,08 \mathrm{E}-02$ & 14,49 & L1M0006TB85 \\
\hline 8 & 0 & 0 & 0,006 & 85 & $2,08 \mathrm{E}-02$ & 14,49 & L1M0006TB85 \\
\hline 9 & 0 & 0 & 0,006 & 85 & $2,08 \mathrm{E}-02$ & 14,49 & L1M0006TB85 \\
\hline \multicolumn{8}{|c|}{ L2 } \\
\hline 1 & -1 & -1 & 0,001 & 70 & $2,42 \mathrm{E}-03$ & 4,19 & L2M0001TB70 \\
\hline 2 & 1 & -1 & 0,011 & 70 & 3,93E-02 & 31,13 & L2M0011TB70 \\
\hline 3 & -1 & 1 & 0,001 & 100 & $1,64 \mathrm{E}-03$ & 3,3 & L2M0001TB100 \\
\hline 4 & 1 & 1 & 0,011 & 100 & $2,04 \mathrm{E}-02$ & 17,26 & L2M0011TB100 \\
\hline 5 & 0 & 0 & 0,006 & 85 & $1,21 \mathrm{E}-02$ & 13,38 & L2M0006TB85 \\
\hline 6 & 0 & 0 & 0,006 & 85 & $1,21 \mathrm{E}-02$ & 13,38 & L2M0006TB85 \\
\hline 7 & 0 & 0 & 0,006 & 85 & $1,21 \mathrm{E}-02$ & 13,38 & L2M0006TB85 \\
\hline 8 & 0 & 0 & 0,006 & 85 & $1,21 \mathrm{E}-02$ & 13,38 & L2M0006TB85 \\
\hline 9 & 0 & 0 & 0,006 & 85 & $1,21 \mathrm{E}-02$ & 13,38 & L2M0006TB85 \\
\hline
\end{tabular}

Tabel 15.

Hasil eksperimen expanded stent orde pertama (laniutan)

\begin{tabular}{cccccccl}
\hline \multicolumn{10}{c}{ L3 } \\
\hline 1 & -1 & -1 & 0,001 & 70 & $5,95 \mathrm{E}-03$ & 6,1 & L3M0001TB70 \\
2 & 1 & -1 & 0,011 & 70 & $1,25 \mathrm{E}-01$ & 51,37 & L3M0011TB70 \\
3 & -1 & 1 & 0,001 & 100 & $4,15 \mathrm{E}-03$ & 5,73 & L3M0001TB100 \\
4 & 1 & 1 & 0,011 & 100 & $6,45 \mathrm{E}-02$ & 30,99 & L3M0011TB100 \\
5 & 0 & 0 & 0,006 & 85 & $3,19 \mathrm{E}-02$ & 14,63 & L3M0006TB85 \\
6 & 0 & 0 & 0,006 & 85 & $3,19 \mathrm{E}-02$ & 14,63 & L3M0006TB85 \\
7 & 0 & 0 & 0,006 & 85 & $3,19 \mathrm{E}-02$ & 14,63 & L3M0006TB85 \\
8 & 0 & 0 & 0,006 & 85 & $3,19 \mathrm{E}-02$ & 14,63 & L3M0006TB85 \\
9 & 0 & 0 & 0,006 & 85 & $3,19 \mathrm{E}-02$ & 14,63 & L3M0006TB85 \\
\hline & & & \multicolumn{7}{c}{ L4 } & & \\
\hline 1 & -1 & -1 & 0,001 & 70 & $5,80 \mathrm{E}-03$ & 5,87 & L4M0001TB70 \\
2 & 1 & -1 & 0,011 & 70 & $1,12 \mathrm{E}-01$ & 36,9 & L4M0011TB70 \\
3 & -1 & 1 & 0,001 & 100 & $4,04 \mathrm{E}-03$ & 4,88 & L4M0001TB100 \\
4 & 1 & 1 & 0,011 & 100 & $5,35 \mathrm{E}-02$ & 21,66 & L4M0011TB100 \\
5 & 0 & 0 & 0,006 & 85 & $2,90 \mathrm{E}-02$ & 16,13 & L4M0006TB85 \\
6 & 0 & 0 & 0,006 & 85 & $2,90 \mathrm{E}-02$ & 16,13 & L4M0006TB85 \\
7 & 0 & 0 & 0,006 & 85 & $2,90 \mathrm{E}-02$ & 16,13 & L4M0006TB85 \\
8 & 0 & 0 & 0,006 & 85 & $2,90 \mathrm{E}-02$ & 16,13 & L4M0006TB85 \\
9 & 0 & 0 & 0,006 & 85 & $2,90 \mathrm{E}-02$ & 16,13 & L4M0006TB85 \\
\hline & & & \multicolumn{7}{c}{ L5 } & & \\
\hline 1 & -1 & -1 & 0,001 & 70 & $5,83 \mathrm{E}-03$ & 7,14 & L5M0001TB70 \\
2 & 1 & -1 & 0,011 & 70 & $1,20 \mathrm{E}-01$ & 49,72 & L5M0011TB70 \\
3 & -1 & 1 & 0,001 & 100 & $4,12 \mathrm{E}-03$ & 6,23 & L5M0001TB100 \\
4 & 1 & 1 & 0,011 & 100 & $5,98 \mathrm{E}-02$ & 30,74 & L5M0011TB100 \\
5 & 0 & 0 & 0,006 & 85 & $3,01 \mathrm{E}-02$ & 18,01 & L5M0006TB85 \\
6 & 0 & 0 & 0,006 & 85 & $3,01 \mathrm{E}-02$ & 18,01 & L5M0006TB85 \\
7 & 0 & 0 & 0,006 & 85 & $3,01 \mathrm{E}-02$ & 18,01 & L5M0006TB85 \\
8 & 0 & 0 & 0,006 & 85 & $3,01 \mathrm{E}-02$ & 18,01 & L5M0006TB85 \\
9 & 0 & 0 & 0,006 & 85 & $3,01 \mathrm{E}-02$ & 18,01 & L5M0006TB85 \\
\hline & & & & & & &
\end{tabular}

1. Model Respon Curvature Index dan Model Respon Von Mises Terhadap L1

a. Model Respon Curvature Index $\hat{y}_{\mathrm{CI}}=0,02392+0,02429 x_{1}-0,00805 x_{2}$

b. Model Respon Von Mises

$$
\hat{\mathrm{y}}_{\mathrm{VM}}=14,3201+8,952 x_{1}-0,835 x_{2}
$$

2. Model Respon Curvature Index dan Model Respon Von Mises Terhadap L2

a. Model Respon Curvature Index $\hat{\mathrm{y}}_{\mathrm{CI}}=0,01382+0,01389 x_{1}-0,00492 x_{2}$

b. Model Respon Von Mises

$$
\hat{\mathrm{y}}_{\mathrm{VM}}=13,643+10,23 x_{1}-3,69 x_{2}
$$

3. Model Respon Curvature Index dan Model Respon Von Mises Terhadap L3

a. Model Respon Curvature Index $\hat{y}_{\mathrm{CI}}=0,03984+0,04474 x_{1}-0,01547 x_{2}$

b. Model Respon Von Mises

$$
\hat{\mathrm{y}}_{\mathrm{VM}}=18,6+17,63 x_{1}-5,19 x_{2}
$$

4. Model Respon Curvature Index dan Model Respon Von Mises Terhadap L4

a. Model Respon Curvature Index $\hat{\mathrm{y}}_{\mathrm{CI}}=0,03565+0,03901 x_{1}-0,01515 x_{2}$

b. Model Respon Von Mises

$$
\hat{y}_{\mathrm{VM}}=16,662+11,95 x_{1}-4,06 x_{2}
$$


5. Model Respon Curvature Index dan Model Respon Von Mises Terhadap L5

a. Model Respon Curvature Index $\hat{\mathrm{y}}_{\mathrm{CI}}=0,03786+0,04257 x_{1}-0,01561 x_{2}$

b. Model Respon Von Mises

$$
\hat{\mathrm{y}}_{\mathrm{VM}}=20,43+16,77 x_{1}-4,97 x_{2}
$$

Dilakukan pengujian statistik menggunakan Analysis of Variance (ANOVA) untuk mengetahui faktor-faktor yang signifikan pada tiap model respon.

Tabel 16.

Hasil ANOVA orde pertama pada respon Curvature Index (expanded stent)

\begin{tabular}{lcccccc}
\hline \multirow{2}{*}{ Source } & \multirow{2}{*}{ DF } & $\begin{array}{c}\text { P-Value } \\
\text { L1 }\end{array}$ & $\begin{array}{c}\text { P-Value } \\
\text { L2 }\end{array}$ & $\begin{array}{c}\text { P-Value } \\
\text { L3 }\end{array}$ & $\begin{array}{c}\text { P-Value } \\
\text { L4 }\end{array}$ & $\begin{array}{c}\text { P-Value } \\
\text { L5 }\end{array}$ \\
\hline Linear & 2 & 0,001 & 0,002 & 0,003 & 0,004 & 0,004 \\
Momen & 1 & 0,001 & 0,001 & 0,001 & 0,002 & 0,002 \\
Tebal & 1 & 0,073 & 0,065 & 0,104 & 0,086 & 0,1 \\
Curvature & 1 & 0,181 & 0,223 & 0,096 & 0,142 & 0,106 \\
\hline
\end{tabular}

Tabel 17.

Hasil ANOVA orde pertama pada respon Von Mises (expanded stent)

\begin{tabular}{l|c|c|c|c|c|c}
\hline Source & DF & $\begin{array}{c}\text { P-Value } \\
\text { L1 }\end{array}$ & $\begin{array}{c}\text { P-Value } \\
\text { L2 }\end{array}$ & $\begin{array}{c}\text { P-Value } \\
\text { L3 }\end{array}$ & $\begin{array}{c}\text { P-Value } \\
\text { L4 }\end{array}$ & $\begin{array}{c}\text { P-Value } \\
\text { L5 }\end{array}$ \\
\hline Linear & 2 & 0 & 0,001 & 0,005 & 0 & 0,001 \\
\hline Momen & 1 & 0 & 0 & 0,002 & 0 & 0,001 \\
\hline Tebal & 1 & 0,001 & 0,033 & 0,177 & 0,035 & 0,092 \\
\hline Curvature & 1 & 0,003 & 0,775 & 0,031 & 0,6 & 0,101 \\
\hline
\end{tabular}

Tabel 18

Uji kecukupan Model Order Pertama

\begin{tabular}{ccccc}
\hline \multirow{2}{*}{ Respon } & \multicolumn{2}{c}{ P-value curvature } & \multirow{2}{*}{$\alpha$} & \multirow{2}{*}{ Status } \\
\cline { 2 - 3 } & Curvature index & Von mises & & \\
\hline L1 & 0,181 & 0,003 & 0,05 & Reject $\mathrm{H}_{0}$ \\
L2 & 0,223 & 0,775 & 0,05 & Fail to Reject $\mathrm{H}_{0}$ \\
L3 & 0,096 & 0,031 & 0,05 & Reject $\mathrm{H}_{0}$ \\
L4 & 0,142 & 0,6 & 0,05 & Fail to Reject $\mathrm{H}_{0}$ \\
L5 & 0,106 & 0,101 & 0,05 & Fail to Reject $\mathrm{H}_{0}$ \\
\hline
\end{tabular}

Rancangan orde dua menggunakan central compisiteb design (CCD), yang disusun menggunakan rancangan orde pertama ditambah empat axial point, sehingga jumlah test run yang harus dilakukan adalah 13 eksperimen. Dengan jumlah faktor $=2$, nilai a yang harusnya digunakan adalah $\sqrt{ } 2$ atau 1,4142 .
Tabel 19.

Hasil eksperimen expanded stent orde kedua

\begin{tabular}{|c|c|c|c|c|c|c|c|}
\hline \multicolumn{8}{|c|}{ L1 } \\
\hline \multirow{2}{*}{$\begin{array}{l}\text { Run } \\
\text { Test }\end{array}$} & \multicolumn{2}{|c|}{$\begin{array}{c}\text { Coded } \\
\text { Variables }\end{array}$} & \multicolumn{2}{|c|}{$\begin{array}{l}\text { Uncoded } \\
\text { Variables }\end{array}$} & \multicolumn{2}{|c|}{ Response } & \multirow{2}{*}{ Kode Parameter } \\
\hline & Momen & Tebal & $\begin{array}{l}\text { Momen } \\
\text { (N.mm) }\end{array}$ & $\begin{array}{l}\text { Tebal } \\
(\mathrm{mm})\end{array}$ & $\underset{(\mathrm{rad} / \mathrm{mm})}{\mathrm{CI}}$ & $\begin{array}{c}\mathrm{VM} \\
(\mathrm{MPa})\end{array}$ & \\
\hline 1 & -1 & -1 & 0,001 & 70 & $4,09 \mathrm{E}-03$ & 5,88 & L1M0001TB70 \\
\hline 2 & 1 & -1 & 0,011 & 70 & $6,75 \mathrm{E}-02$ & 24,02 & L1M0011TB70 \\
\hline 3 & -1 & 1 & 0,001 & 100 & $2,88 \mathrm{E}-03$ & 4,44 & L1M0001TB100 \\
\hline 4 & 1 & 1 & 0,011 & 100 & $3,66 \mathrm{E}-02$ & 22,11 & L1M0011TB100 \\
\hline 5 & $-1,41$ & 0 & 0,0011 & 85 & $3,74 \mathrm{E}-03$ & 6,69 & L1M00011TB85 \\
\hline 6 & $-1,41$ & 0 & 0,013 & 85 & $6,39 \mathrm{E}-02$ & 34,84 & L1M0013TB85 \\
\hline 7 & 0 & $-1,41$ & 0,006 & 63,79 & $2,94 \mathrm{E}-02$ & 15,05 & L1M0006TB63 \\
\hline 8 & 0 & 1,41 & 0,006 & 106,21 & $1,65 \mathrm{E}-02$ & 13,81 & L1M0006TB106 \\
\hline 9 & 0 & 1 & 0,006 & 85 & $2,08 \mathrm{E}-02$ & 14,49 & L1M0006TB85 \\
\hline 10 & 0 & 1 & 0,006 & 85 & $2,08 \mathrm{E}-02$ & 14,49 & L1M0006TB85 \\
\hline 11 & 0 & 1 & 0,006 & 85 & $2,08 \mathrm{E}-02$ & 14,49 & L1M0006TB85 \\
\hline 12 & 0 & 1 & 0,006 & 85 & $2,08 \mathrm{E}-02$ & 14,49 & L1M0006TB85 \\
\hline 13 & 0 & 1 & 0,006 & 85 & $2,08 \mathrm{E}-02$ & 14,49 & L1M0006TB85 \\
\hline
\end{tabular}

1. Model Respon Curvature Index dan Model Respon Von Mises Terhadap L1

a. Model Respon Curvature Index

$$
\hat{\mathrm{y}}_{\mathrm{CI}}=0,02083+0,022772 x_{1}-0,006311 x_{2}+
$$
$0,006336 x_{1}^{2}+0,00091 x_{2}{ }_{2}-0,00744 x_{1} x_{2}$

b. Model Respon Von Mises

$\hat{\mathrm{y}}_{\mathrm{VM}}=14,487+9,453 x_{1}-0,637 x_{2}+$ $2,267 x_{1}^{2}-0,9 x_{2}^{2}-0,12 x_{1} x_{2}$

2. Model Respon Curvature Index dan Model Respon Von Mises Terhadap L3

a. Model Respon Curvature Index $\hat{\mathrm{y}}_{\mathrm{CI}}=0,03187+0,04206 x_{1}-0,01234 x_{2}+$ $0,01475+0,00287 x_{2}^{2}-0,01457 x_{1} x_{2}$

b. Model Respon Von Mises

$\hat{\mathrm{y}}_{\mathrm{VM}}=14,63+18,622 x_{1}-4,091 x_{2}+$ $9,308 x^{2}+1,496 x^{2}{ }_{2}-5 x_{1} x_{2}$

Selanjutnya, dilakukan pengujian statistik menggunakan Analysis of Variance (ANOVA) untuk mengetahui faktor-faktor yang signifikan pada tiap model respon.

Tabel 20.

Hasil ANOVA orde kedua pada respon Curvature Index (expanded stent)

\begin{tabular}{lccc}
\hline Source & DF & $\begin{array}{c}\text { P-Value } \\
\text { L1 }\end{array}$ & $\begin{array}{c}\text { P-Value } \\
\text { L3 }\end{array}$ \\
\hline Linear & 2 & 0 & 0 \\
Momen & 1 & 0 & 0 \\
Tebal & 1 & 0 & 0,386 \\
Square & 2 & 0,001 & 0,03 \\
Momen*Momen & 1 & 0 & 0,018 \\
Tebal*Tebal & 1 & 0,366 & 0,262 \\
2-Way Interaction & 1 & 0,001 & 0,906 \\
\hline
\end{tabular}


Tabel 21

Hasil ANOVA orde 2 pada respon Von Mises (expanded stent)

\begin{tabular}{lccc}
\hline Source & DF & $\begin{array}{c}\text { P-Value } \\
\text { L1 }\end{array}$ & $\begin{array}{c}\text { P-Value } \\
\text { L3 }\end{array}$ \\
\hline Linear & 2 & 0 & 0 \\
Momen & 1 & 0 & 0 \\
Tebal & 1 & 0 & 0 \\
Square & 2 & 0 & 0,003 \\
Momen*Momen & 1 & 0 & 0 \\
Tebal*Tebal & 1 & 0,131 & 0 \\
2-Way Interaction & 1 & 0 & 0,168 \\
\hline
\end{tabular}

Hasil pengujian menggunakan ANOVA juga menghasilkan nilai koefisien determinasi () yang menggambarkan besar pengaruh variabel-variabel bebas (faktor) yang digunakan terhadap variabel respon. Semakin besar nilai , maka semakin besar pengaruh variabel bebas tersebut terhadap variasi respon.

Tabel 22.

Nilai model dasar orde pertama (expanded stent)

\begin{tabular}{cccc}
\hline \multicolumn{4}{c}{$\mathrm{L} 2$} \\
\hline Respon & $\mathrm{R}^{2}$ & $\mathrm{R}^{2}(\mathrm{adj})$ & $\mathrm{R}^{2}-\mathrm{R}^{2}(\mathrm{adj})$ \\
\hline Curvature index & $88,41 \%$ & $84,55 \%$ & $3,86 \%$ \\
Von mises & $91,68 \%$ & $88,91 \%$ & $2,77 \%$ \\
\hline \multicolumn{4}{c}{$\mathrm{L} 4$} \\
\hline Curvature index & $84,27 \%$ & $79,03 \%$ & $5,24 \%$ \\
Von mises & $92,20 \%$ & $89,60 \%$ & $2,60 \%$ \\
\hline \multicolumn{4}{c}{$\mathrm{L} 5$} \\
\hline Curvature index & $84,17 \%$ & $78,90 \%$ & $5,27 \%$ \\
Von mises & $89,24 \%$ & $85,66 \%$ & $3,58 \%$ \\
\hline
\end{tabular}

Tabel 23.

Nilai model dasar orde kedua (expanded stent)

\begin{tabular}{cccc}
\hline \multicolumn{4}{c}{$\mathrm{L} 1$} \\
\hline Respon & $\mathrm{R}^{2}$ & $\mathrm{R}^{2}(\operatorname{adj})$ & $\mathrm{R}^{2}-\mathrm{R}^{2}(\operatorname{adj})$ \\
Curvature index & $99,14 \%$ & $98,52 \%$ & $0,62 \%$ \\
Von mises & $96,64 \%$ & $94,23 \%$ & $2,41 \%$ \\
\hline \multicolumn{4}{c}{$\mathrm{L} 3$} \\
\hline Curvature index & $99,24 \%$ & $98,69 \%$ & $0,55 \%$ \\
Von mises & $98,74 \%$ & $97,84 \%$ & $0,90 \%$ \\
\hline
\end{tabular}

Validasi Model Regresi untuk Respon Curvature Index dan Von Mises. Kemudian, dilakukan pengujian hipotesis menggunakan F-test: Two Sample for Variances.

Tabel 24.

F-test: Two Sample for Variances

\begin{tabular}{ccccc}
\hline Respons & F & Fcritical & Status & Kode \\
\hline CI & 1,01194 & 2,68664 & Fail to Reject H0 & \multirow{2}{*}{ L1 } \\
VM & 1,0384 & 2,68664 & Fail to Reject H0 & \\
CI & 1,1309 & 2,68664 & Fail to Reject H0 & \multirow{2}{*}{ L2 } \\
VM & 1,08993 & 3,4381 & Fail to Reject H0 & \\
CI & 1,01096 & 2,68664 & Fail to Reject H0 & \multirow{2}{*}{ L3 } \\
VM & 1,01661 & 2,68664 & Fail to Reject H0 & \\
CI & 1,18648 & 3,4381 & Fail to Reject H0 & \multirow{2}{*}{ L4 } \\
VM & 1,08494 & 3,4381 & Fail to Reject H0 & \\
CI & 1,18819 & 3,4381 & Fail to Reject H0 & \multirow{2}{*}{ L5 } \\
VM & 1,12079 & 3,4381 & Fail to Reject H0 & \\
\hline
\end{tabular}

Curvature Index dan Von Mises (expanded stent)

Selanjutnya, dilakukan t-test: Two-Sample Assuming Equal Variances.

Tabel 25.

t-Test: Two-Sample Assuming Equal Variances Curvature Index dan Von Mises

(expanded stent)

\begin{tabular}{c|c|c|c|c}
\hline Respons & t-stst & tcritical & Status & \multirow{2}{*}{ Kode } \\
\cline { 1 - 4 } CI & 0,00171 & 2,0639 & Fail to Reject H0 & \multirow{2}{*}{ L1 } \\
\cline { 1 - 4 } VM & 0,0007 & 2,0639 & Fail to Reject H0 & \\
\hline CI & $-0,00014$ & 2,11991 & Fail to Reject H0 & \multirow{2}{*}{ L2 } \\
\hline VM & $-3,00 \mathrm{E}-07$ & 2,11991 & Fail to Reject H0 & \\
\hline CI & 0,00216 & 2,0639 & Fail to Reject H0 & \multirow{2}{*}{ L3 } \\
\hline VM & $3,35 \mathrm{E}-03$ & 2,0639 & Fail to Reject H0 & \\
\hline CI & $-4,49 \mathrm{E}-05$ & 2,11991 & Fail to Reject H0 & \multirow{2}{*}{ L4 } \\
\hline VM & $-9,80 \mathrm{E}-05$ & 2,11991 & Fail to Reject H0 & \\
\hline CI & 0,000268 & 2,11991 & Fail to Reject H0 & \multirow{2}{*}{ L5 } \\
\cline { 1 - 3 } VM & 0,0005 & 2,11991 & Fail to Reject H0 & \\
\hline
\end{tabular}

Surface plot dapat menggambarkan letak dari titik-titik optimal dari tiap respon terhadap parameter-parameter yang mempengaruhi. Optimasi Kombinasi Parameter Desain Crimped Stent L1 sampai dengan L5.Surface plot yang didapatkan dari model orde pertama dan orde 


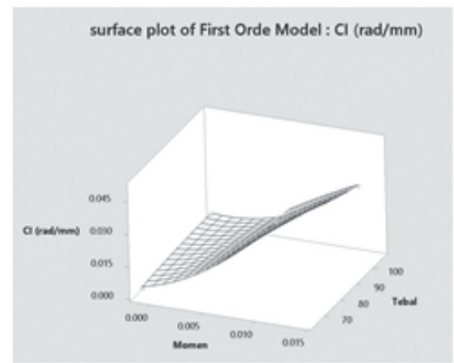

(a)

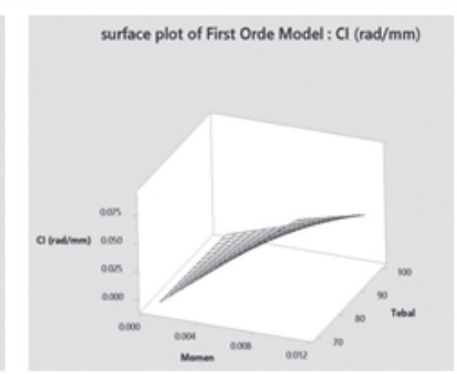

(b)

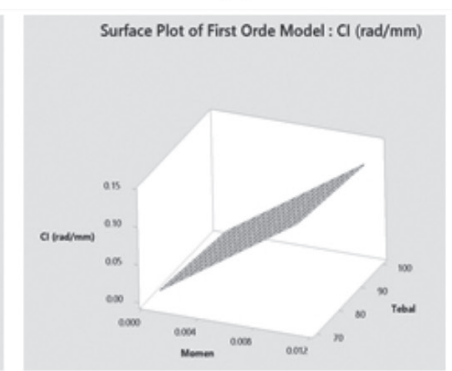

(c)
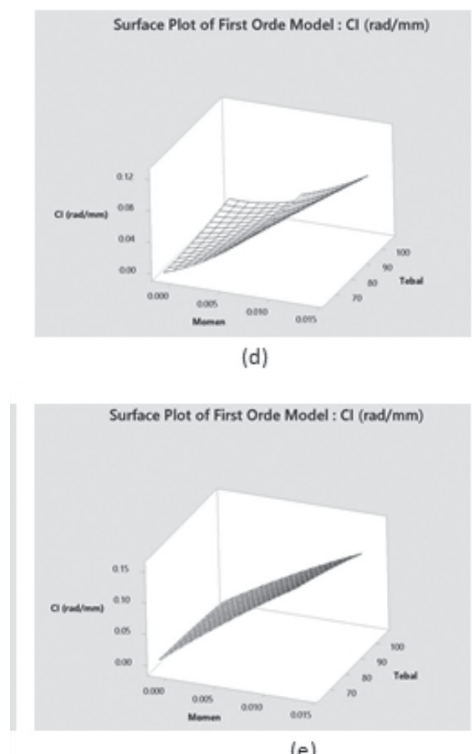

(e)

Gambar 4.

Surface Plot Crimped Stent Curvature Index:

(a) L1, (b) L2, (c) L3, (d) L4, dan (e) L5

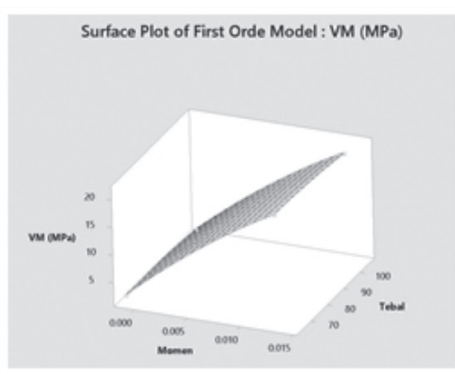

(a)

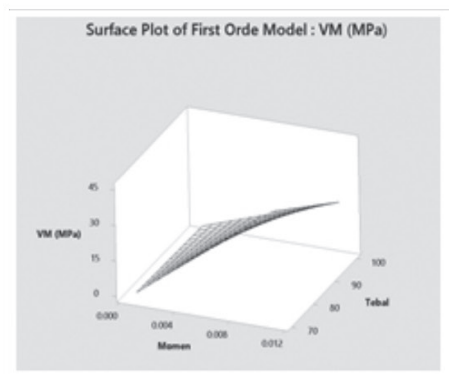

(b)

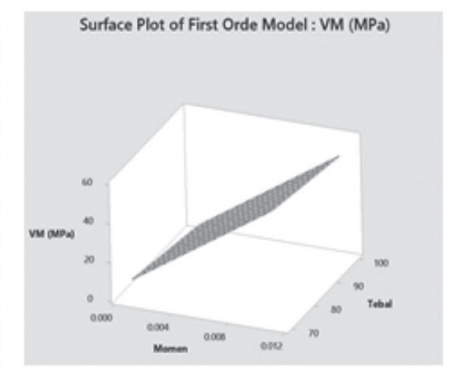

(c)

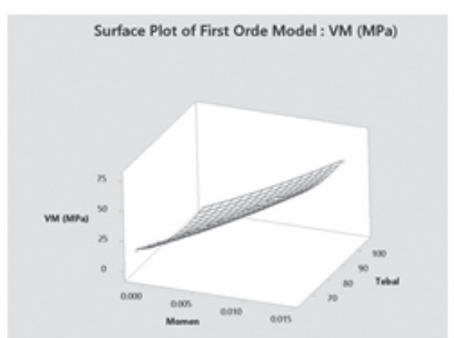

(d)

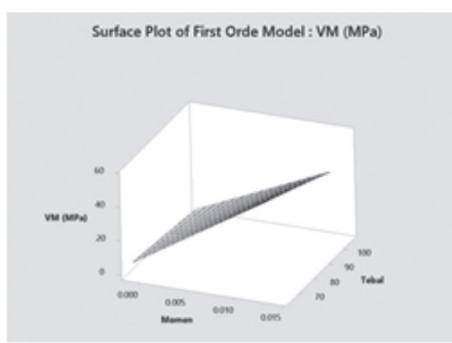

(e)

Gambar 5.

Surface Plot Crimped Stent Von Mises: (a) L1, (b) L2, (c) L3, (d) L4, dan (e) L5 
Selanjutnya, dilakukan optimasi parameter desain pada crimped stent dilakukan menggunakan bantuan response optimizer

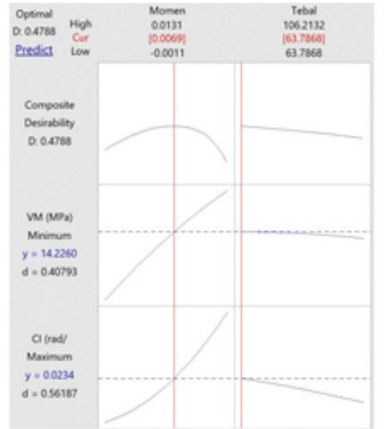

(a)

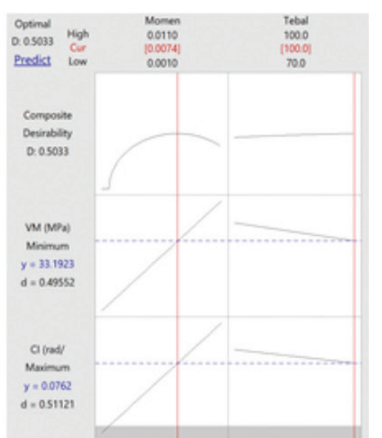

(c)

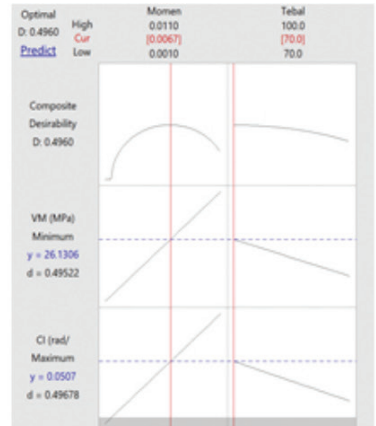

(b)

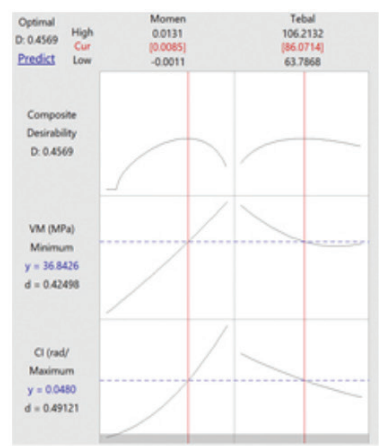

(d)

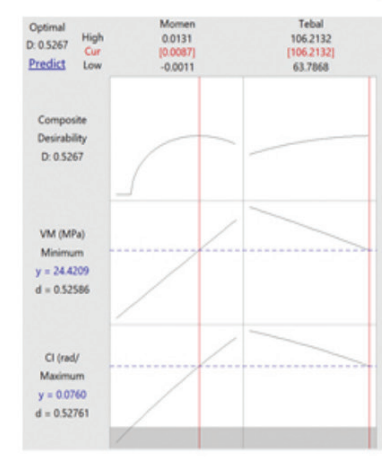

(e)

Gambar 6.

Optimization Plot pada Keseluruhan Respon

(a) L1, (b) L2, (c) L3, (d) L4, dan (e) L5

Hasil nilai parameter desain serta nilai prediksi respon optimal ditunjukkan pada Tabel 26 di bawah ini.

Tabel 26.

Parameter optimal keseluruhan respon crimped stent

\begin{tabular}{ccccc}
\hline \multirow{2}{*}{ Kode } & Parameter Optimal & \multicolumn{3}{c}{ Nilai Prediksi Respon } \\
\cline { 2 - 5 } & Momen $(\mathrm{N} . \mathrm{mm})$ & $\begin{array}{c}\text { Tebal } \\
(\mu \mathrm{m})\end{array}$ & $\mathrm{CI}(\mathrm{rad} / \mathrm{mm})$ & $\begin{array}{c}\mathrm{VM} \\
(\mathrm{MPa})\end{array}$ \\
\hline L1 & 0,0069 & 63,7868 & 0,0234 & 14,226 \\
L2 & 0,0067 & 70 & 0,0507 & 26,1306 \\
L3 & 0,0074 & 100 & 0,0762 & 33,1923 \\
L4 & 0,0085 & 86,0714 & 0,048 & 36,8426 \\
L5 & 0,0087 & 106,2132 & 0,076 & 24,4209 \\
\hline
\end{tabular}

Tabel 27.

Perbandingan nilai prediksi keseluruhan respon dengan respon aktual crimped stent

\begin{tabular}{|c|c|c|c|c|}
\hline Kode & Respon & $\begin{array}{c}\text { Nilai } \\
\text { Prediksi }\end{array}$ & $\begin{array}{c}\text { Niali } \\
\text { Aktual } \\
\end{array}$ & Selisih \\
\hline \multirow{2}{*}{ L1 } & Curvature Index $(\mathrm{rad} / \mathrm{mm})$ & 0,0234 & 0,0258 & 0,0024 \\
\hline & Von Mises (Mpa) & 14,226 & 14,6495 & 0,4235 \\
\hline \multirow{2}{*}{$\mathrm{L} 2$} & Curvature Index $(\mathrm{rad} / \mathrm{mm})$ & 0,0507 & 0,0407 & 0,01 \\
\hline & Von Mises (Mpa) & 26,1306 & 17,5256 & 8,605 \\
\hline \multirow{2}{*}{ L3 } & Curvature Index $(\mathrm{rad} / \mathrm{mm})$ & 0,0762 & 0,076 & 0,0002 \\
\hline & Von Mises (Mpa) & 33,1923 & 33,6151 & 0,4228 \\
\hline \multirow{2}{*}{ L4 } & Curvature Index $(\mathrm{rad} / \mathrm{mm})$ & 0,048 & 0,0481 & 0 \\
\hline & Von Mises (Mpa) & 36,8426 & 47,89 & 11,0474 \\
\hline \multirow{2}{*}{ L5 } & Curvature Index $(\mathrm{rad} / \mathrm{mm})$ & 0,076 & 0,08 & 0,004 \\
\hline & Von Mises (Mpa) & 24,4209 & 26,4391 & 2,0182 \\
\hline
\end{tabular}

Perbandingan desain stent L1 sampai dengan L5 dari nilai respon optimal terhadap nilai respon simulasi curvature index dan Tegangan Von Mises yang ditunjukkan pada gambar 10 dan 11.

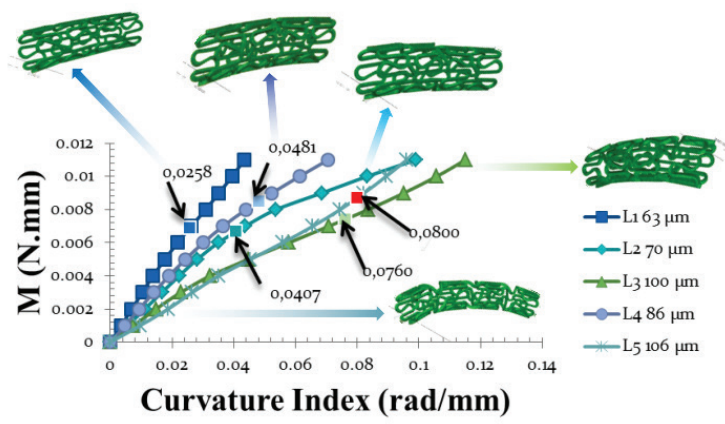

(a)

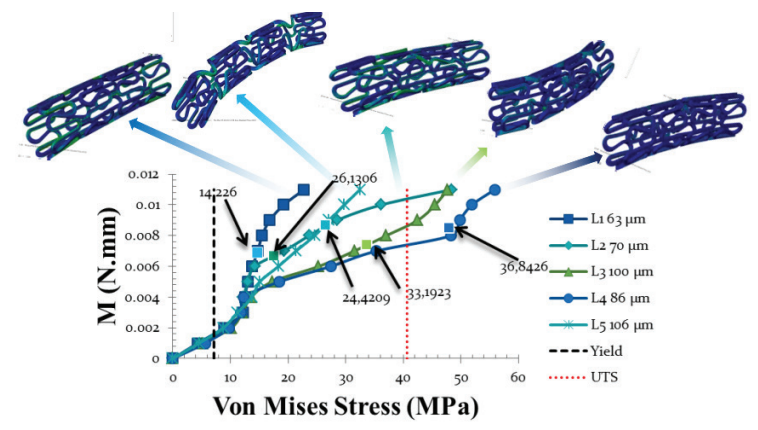

(b)

Gambar 7.

Hasil grafik nilai optmal dan nilai Simulasi Crimped Stent L1 sampai dengan L5: (a) curvature index; (b) Tegangan Von Mises

Optimasi Kombinasi Parameter Desain Expanded Stent L1 sampai dengan L5 ditunjukkan pada Gambar 8 terhadap Curvature Index 
dan Gambar 9 terhadap Von Mises, berikut Gambar surface plot.

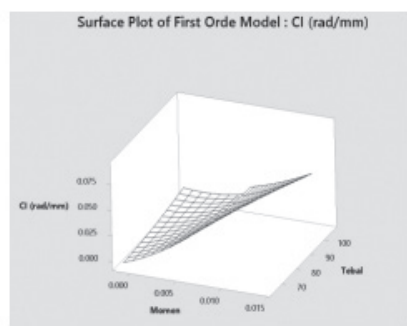

(a)

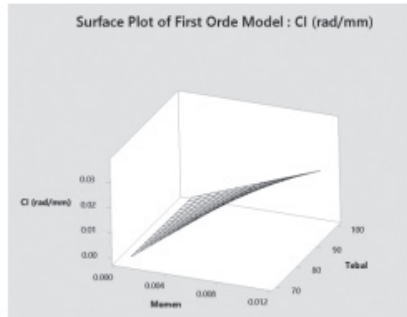

(b)

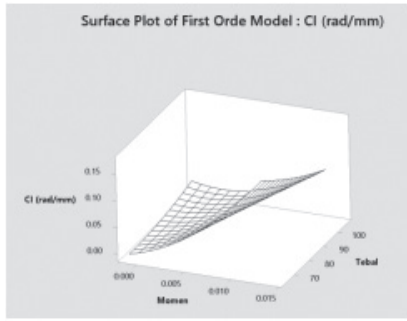

(c)

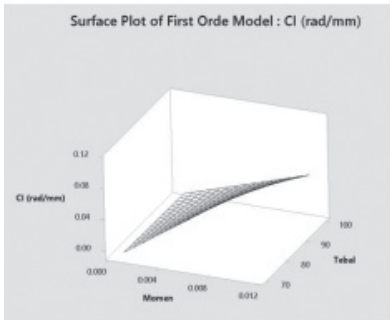

(d)

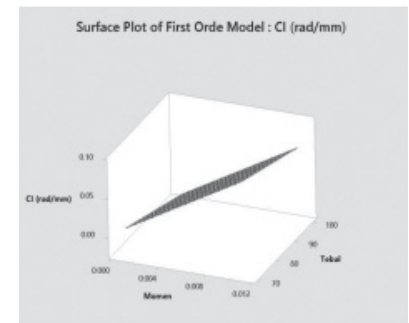

(e)

Gambar 8.

Surface Plot Expanded Stent Curvature Index:

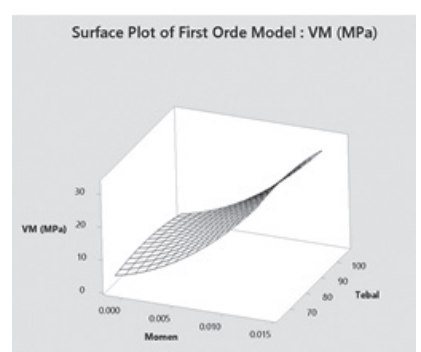

(a)

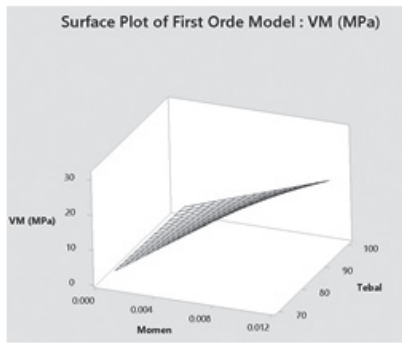

(b)

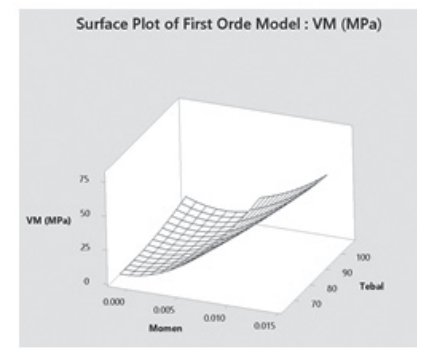

(c)
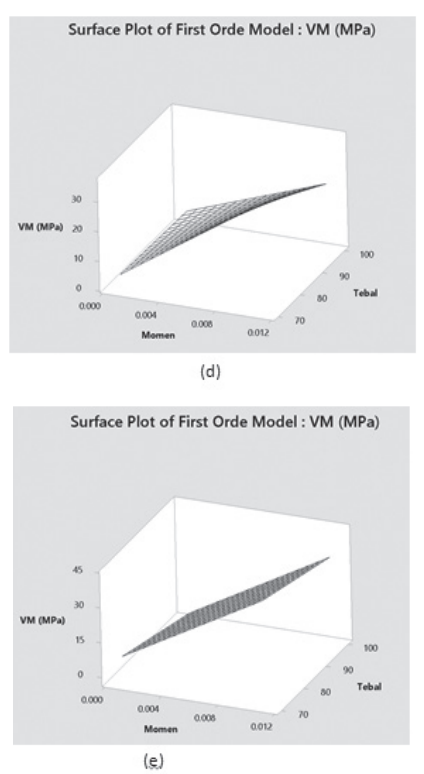

Gambar 9.

Surface Plot Expanded Stent Von Mises: (a) L1, (b) L2, (c) L3, (d) L4, dan (e) L5

(a) L1, (b) L2, (c) L3, (d) L4, dan (e) L5 
Selanjutnya, dilakukan optimasi parameter desain pada Expanded Stent dilakukan menggunakan bantuan response optimizer

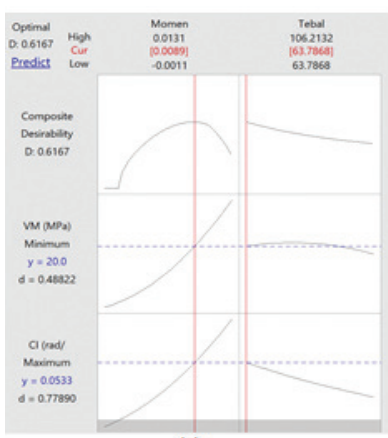

(a)

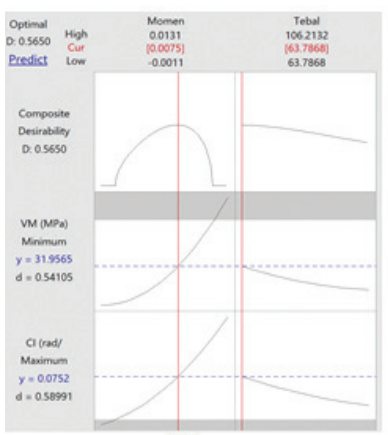

(c)

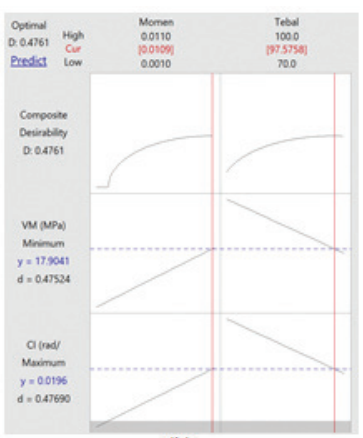

(b)

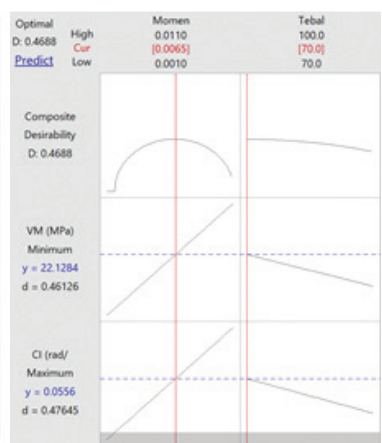

(d)

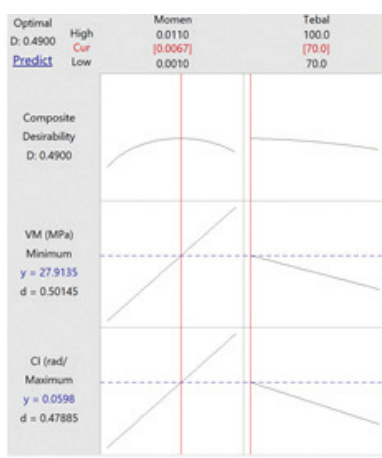

(e)

Gambar 10

Optimization Plot pada Keseluruhan Respon

(a) L1, (b) L2, (c) L3, (d) L4, dan (e) L5

Hasil nilai parameter desain serta nilai prediksi respon optimal ditunjukkan pada Tabel 28 di bawah ini.
Tabel 28

Parameter optimal keseluruhan respon Expanded Stent

\begin{tabular}{ccccc}
\hline \multirow{2}{*}{ Kode } & Parameter Optimal & \multicolumn{3}{c}{ Nilai Prediksi Respon } \\
\cline { 2 - 5 } & Momen $(\mathrm{N} \cdot \mathrm{mm})$ & $\begin{array}{c}\text { Tebal } \\
(\mu \mathrm{m})\end{array}$ & $\mathrm{CI}(\mathrm{rad} / \mathrm{mm})$ & $\begin{array}{c}\text { VM } \\
(\mathrm{MPa})\end{array}$ \\
\hline L1 & 0,0089 & 63,7868 & 0,0533 & 20 \\
L2 & 0,0109 & 97,5758 & 0,0196 & 17,9041 \\
L3 & 0,0075 & 63,7868 & 0,0752 & 31,9565 \\
L4 & 0,0065 & 70 & 0,0556 & 22,1284 \\
L5 & 0,0067 & 70 & 0,0598 & 27,9135 \\
\hline
\end{tabular}

Tabel 29.

Perbandingan nilai prediksi keseluruhan respon dengan respon aktual Expanded Stent

\begin{tabular}{clccc}
\hline \multirow{2}{*}{ Kode } & \multicolumn{1}{c}{ Respon } & $\begin{array}{c}\text { Nilai } \\
\text { Prediksi }\end{array}$ & $\begin{array}{c}\text { Niali } \\
\text { Aktual }\end{array}$ & Selisih \\
\hline \multirow{2}{*}{ L1 } & Curvature Index $(\mathrm{rad} / \mathrm{mm})$ & 0,0533 & 0,05535 & 0,00205 \\
& Von Mises $(\mathrm{Mpa})$ & 20 & 24,6469 & 4,6469 \\
\multirow{2}{*}{ 2 } & Curvature Index $(\mathrm{rad} / \mathrm{mm})$ & 0,0196 & 0,0208 & 0,0012 \\
& Von Mises $(\mathrm{Mpa})$ & 17,9041 & 18,3766 & 0,4725 \\
$\mathrm{~L} 3$ & Curvature Index $(\mathrm{rad} / \mathrm{mm})$ & 0,0752 & 0,0762 & 0,001 \\
& Von Mises $(\mathrm{Mpa})$ & 31,9565 & 34,0203 & 2,0638 \\
\multirow{2}{*}{ 4 } & Curvature Index $(\mathrm{rad} / \mathrm{mm})$ & 0,0556 & 0,0403 & 0,0153 \\
& Von Mises $(\mathrm{Mpa})$ & 22,1284 & 14,4906 & 7,6378 \\
L5 & Curvature Index $(\mathrm{rad} / \mathrm{mm})$ & 0,0598 & 0,0485 & 0,0113 \\
& Von Mises $(\mathrm{Mpa})$ & 27,9135 & 19,0668 & 8,8467 \\
\hline
\end{tabular}

Perbandingan desain stent L1 sampai dengan L5 dari nilai respon optimal terhadap nilai respon simulasi curvature index dan Tegangan Von Mises yang ditunjukkan pada gambar 10.

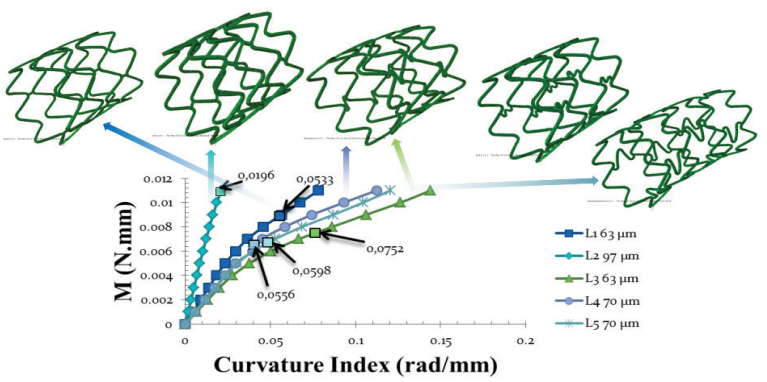

(a)

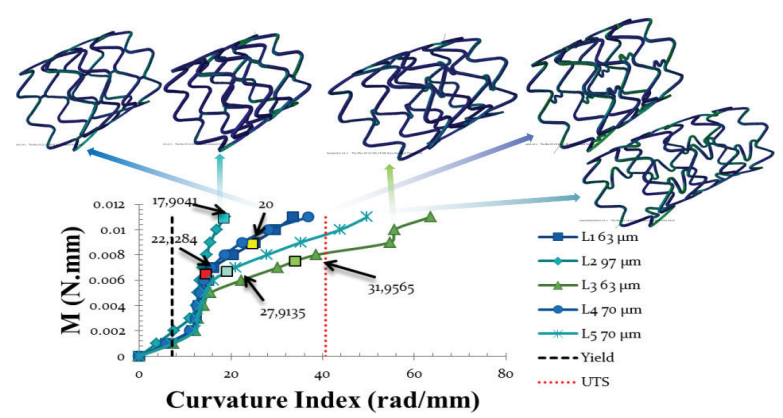

(b)

Gambar 11.

Hasil grafik nilai optmal dan nilai Simulasi expanded stent L1 sampai dengan L5: (a) curvature index; (b) Tegangan Von Mises 
DariGambar10 dapat dilihat perbandingan desain expanded stent pada L1 sampai dengan L5 terhadap respon curvature index dan tegangan von mises yang sudah disimulasikan dengan nilai prediksi yang optimal. Pada curvature index dari desain L1 sampai dengan L5 dapat dilihat desain yang curvature index yang berpengaruh pada fleksibilitas terbaik adalah di desain L1, L3, L4, dan L5. Sementara pada desain L2 fleksibilitasnya terlalu kaku tidak dapat digunakan.

Sedangkan pada tegangan von mises pada desain L1 sampai dengan L5 dapat dilihat hasil tegangan von mises di bawah UTS dan di atas yield strength sehingga dapat dikatakan dalam kondisi aman.

\section{SIMPULAN}

Berdasarkan hasil dan pembahasan penelitian yang telah dilakukan mengenai optimasi desain polimer stent dengan material PLA untuk memperoleh fleksibilitas terbaik dengan tegangan maksimum von mises dalam batas aman yang dilakukan menggunakan metode response surface, dapat disimpulkan Pertama, Nilai desain optimal untuk mendapatkan fleksibilitas crimped stent terbaik pada L1 sampai dengan L5 dengan tegangan maksimum dalam batas aman adalah bending momen sebesar 0,0069 N.mm pada ketebalan $63,78 \mu \mathrm{m}$ L1, 0,0067 N.mm pada ketebalan 70 $\mu \mathrm{m}$ L2, 0,0074 N.mm pada ketebalan $100 \mu \mathrm{m}$ L3, 0,0085 N.mm pada ketebalan $86,07 \mu \mathrm{m}$ L4, dan 0,0087 N.mm pada ketebalan $106 \mu \mathrm{m}$ L5. Nilai parameter tersebut menghasilkan prediksi respon Curvature Index sebesar 0,0234 rad/mm dan tegangan Von Mises sebesar 14,226 MPa pada desain L1, Curvature Index sebesar 0,0507 $\mathrm{rad} / \mathrm{mm}$ dan tegangan Von Mises sebesar 26,1306 MPa pada desain L2, Curvature Index sebesar 0,0762 rad/ $\mathrm{mm}$ dan tegangan Von Mises sebesar 33,1923 MPa pada desain L3, Curvature Index sebesar 0,048 $\mathrm{rad} / \mathrm{mm}$ dan tegangan Von Mises sebesar 36,8426 MPa pada desain L4, dan Curvature Index sebesar 0,076 rad/mm dan tegangan Von Mises sebesar 24,4209 MPa pada desain L5. Dari desain stent L1 sampai dengan L5 yang terbaik fleksibilitasnya ada di desain L3 dan L5.
Kedua, Nilai desain optimal untuk mendapatkan fleksibilitas expanded stent terbaik pada L1 sampai L5 dengan tegangan maksimum dalam batas aman adalah bending momen sebesar 0,0089 N.mm pada ketebalan 63,78 $\mu \mathrm{m}$ L1, 0,0109 N.mm pada ketebalan 97,57 $\mu \mathrm{m}$ L2, 0,0075 N.mm pada ketebalan 63,78 $\mu \mathrm{m}$ L3, 0,0065 N.mm pada ketebalan $70 \mu \mathrm{m}$ L4, dan 0,0067 N.mm pada ketebalan $70 \mu \mathrm{m}$ L5.

Ketiga, Nilai parameter tersebut menghasilkan prediksi respon Curvature Index sebesar 0,0533 $\mathrm{rad} / \mathrm{mm}$ dan tegangan Von Mises sebesar $20 \mathrm{MPa}$ pada desain L1, Curvature Index sebesar 0,0196 rad/mm dan tegangan Von Mises sebesar 17,9041 MPa pada desain L2, Curvature Index sebesar 0,0752 $\mathrm{rad} / \mathrm{mm}$ dan tegangan Von Mises sebesar 31,9565 MPa pada desain L3, Curvature Index sebesar 0,0556 rad/ mm dan tegangan Von Mises sebesar 22,1284 MPa pada desain L4, dan Curvature Index sebesar 0,0598 $\mathrm{rad} / \mathrm{mm}$ dan tegangan Von Mises sebesar 27,9135MPa pada desain L5. Dari desain stent L1 sampai dengan L5 yang terbaik fleksibilitasnya ada di desain L1, L3, L4 dan L5.

\section{DAFTAR PUSTAKA}

Akbari, R. A. 2013. Analisis Pengaruh Suhu Terhadap Kekuatan Surface Metal Seal (SMS) Packoff pada Unitized Wellhead Menggunakan Metode Elemen Hingga. Skripsi. Universitas Gadjah Mada. Yogyakarta.

ASTM D 638, 2000, Standard Test Method for tensile Properties of Plastics, ASTM International.

Bae, I.H., Lim, K.S., Park, J.K., Park, D.S., Lee, S.Y., Jang, E.U., Ji, M.S., Sim, Hong, Y.J., Ahn, Y., Park, J.C., Cho, J.G., Kang, J.C., Kim, I.S., Nah, J.W., dan Jeong, M.H., 2014, Mechanical Behavior and In Vivo Properties of Newly Designed Bare Metal Stent for Enhanced Flexibility, Journal of Industrial and Engineering Chemistry, 21, pp. 1295-1300.

Beule, M.D., 2008, Finite Element Stent Design, Thesis, Ghet University, Belgium. 
Biotronik, 2017, PRO Kinetic Energy, http://www.biotronik.com/enus/ products/ vi/coronary/pro-kineticenergy (diakses online 15 Juni 2017).

Bobel A. C., Petisco S., Sarasua J. R., Wang W., and Mchugh P. E., 2015, Computational Bench Testing to Evaluate the Short-Term Mechanical Performance of a Polymeric Stent, Cardiovascular Engineering and Technology, vol. 6, No.4, pp 519-532.

Erbel, R., Haude, M., Hopp, W.H., Franzen, D., Rupprecht, H.J., Heublein, B., Fischer, K., Jaegere, P.D, Serruys, P., Rutsch, W., Prost, P., 1998, CoronaryArtery Stenting Compared with Balloon Angioplasty for Restenosis After Initial Balloon Angioplasty, The New England Journal of Medicine, Vol. 339, No. 23, pp. 1672-1678.

Fogarotto, F., 2011, Finite Element Analysis of Coronary Artery Stenting, Thesis, Hermawan, H., Dubé, D, dan Mantovani, D., 2010, Developments in metallic biodegradable stents, Acta Biomaterialia, vol. 6, pp. 16931697.

Hadiyat, M. A., 2012, Response-surface dan Taguchi: Sebuah Alternatif atau Kompetisi dalam Optimasi Secara Praktis, Prosiding Seminar Nasional Industrialisasi Madura, pp. 33453354.

Hoang, V., 2004, Stent Design and Engineer Coating Over Flow Removal Tool, http://www.me.ucr.edu/ sendesign/0405/team3/Stent_ Design.doc, diakses secara online pada 27 Mei 2017.

Kementerian Kesehatan RI, 2013, Situasi Kesehatan Jantung, http:// www.depkes.go.id/download. php? file=download / pusdatin / infodatin/in fodatin-jantung.pdf (diakses online 1 Maret 2018).
Li, N., Zhang, H., Ouyang, H., 2009, Shape Optimization of Coronary Artery Stent Based on a Parametric Model, Finite Elements in Analysis and Design, Vol. 45, pp. 469-475.

Montgomery, D.C. dan Runger, G.C., 2003, Applied Statistics and Probability for Engineers, 3rd ed., John Wiley \& Sons, New York.

Myers, R. H., Montgomery, D. C., \& Anderson-Cook, C. M., 2009, Response surface methodology: process and product optimization using designed experiments, John Wiley \& Sons, New York.

Nursetyati, P. S. 2017. Optimasi Parameter Desain BMS Berbahan Baku Cobalt Chromium L605 untuk Memperoleh Fleksibilitas Terbaik Menggunakan Metode Response Surface. Skripsi. Universitas Gadjah Mada. Yogyakarta.

Pant, S., Bressloff, N.W., Limbert, G., 2012, Geometry Parameterization and Multidisciplinary Constrained Optimization of Coronary Stents, Biomech Model Mechanobiol, Vol. 11, pp. 61-81.

Petrini, L., Migliavacca, Auricchio, F., dan Dubini, G., 2004, Numerical Investigation of the Intravascular Coronary Stent Flexibility, Journal of Biomechanics, vol. 37, pp. 495-501.

Sangiorgi, G., Melzi, G., Agostoni, P., Cola, C., Clementi, F., Romitelli, P., Virmani. R., Colombo, A., 2007, Engineering Aspects of Stents Design and Their Translation into Clinical Practice, Ann Ist Super Sanita, Vol. 43, No. 1.

Sastranegara, A., 2009, Mengenal Uji Tarik dan Sifat-sifat Mekanik Logam, http://www.infometrik.com/ wpcontent/uploads/2009/09/ Mengenalujitarik.pdf, [Diakses pada 17 Januari 2018].

Schiavone, A., Qiu, T., dan Zhao, L., 2017, Crimping and deployment of 
metallic and polymeric stents-finite element modelling, Vessel Plus Journal, vol. 1, pp. 12-21.

Septiani, E. G., 2017, Optimasi Parameter Desain Stent Berbahan baku Poly-L-Lactic-Acid (PLLA) untuk Memperoleh Fleksibilitas Terbaik Menggunakan Metode Response Surface, Skripsi, Universitas Gadjah Mada.

Sivaros, Milkey, K. R., Samsudin, A. R., Dubey, A. K., dan Kidd., P., 2014, Comparison Between Taguchi Method and Response Surface Methodology (RSM) in Modelling CO2 Laser Machining, Jordan Journal of Mechanical and Industrial Engineering, vol. 8, iss. 1, pp. 35-42.

Tontowi, A.E., Ikra, P., dan Siswomihardjo, W., 2013, Mapping of Cardivascular Stent Demand of Several Hospitals in Indonesia and Its Forecasting, Proceeding of ICICI 2013, Bandung, Indonesia Università degli Studi di Pavia, Italia.

Utami, A. S. M. K., 2017, Optimasi Parameter Desain Stent Dengan Linkage Terpilih
Berbahan Baku Poly-L-Lactic Acid (PLLA) untuk Memperoleh Fleksibilitas Terbaik Menggunakan Metode Response Surface, Skripsi, Universitas Gadjah Mada.

WHO, 2015, World heath statistics 2015, https://doi.org/ISBN 978 92, diakses secara online 8 Agustus 2017.

Wu, W., Yang, D.Z., Qi, M., Wang, W.Q., 2007, An FEA Method to Study Flexibility of Expanded Coronary Stents, Journal of Materials Processing Technology, 184, pp. 447-150.

Young, P.G., Beresford-West, T.B.H., Coward, S.R.L., Notarberardino, B., Walker, B., Abdul-Aziz, A., 2008, An Efficient Approach to Converting Three Dimensional Image Data into Highly Accurate Computational Models, Philosophical Transactions of The Royal Society, Vol. 366, pp. 3155-1373. (

Zainuri, A., Sujita, Popo, A.L., 2010, Tegangan Maksimum dan Faktor Keamanan pada Poros Engkol Daihatsu Zebra Espass Berdasarkan Metode Numerik, Momen 